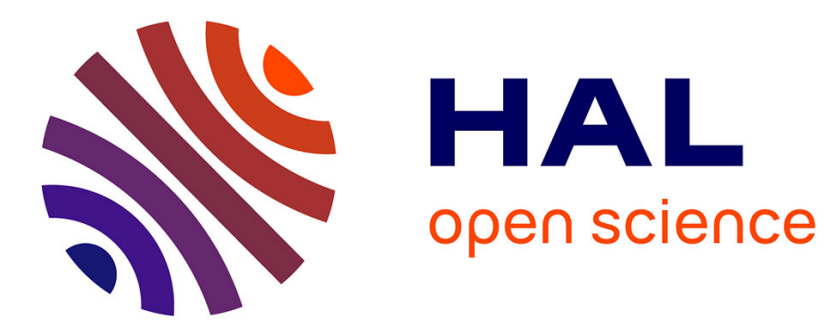

\title{
Electron Beam Charging of Insulators with Surface Layer and Leakage Currents
}

Nadège Cornet, Dominique Gouriot, Christelle Guerret-Piecourt, Denyse Juvé, Daniel Tréheux, Matthieu Touzin, Hans-Joachim Fitting

\section{- To cite this version:}

Nadège Cornet, Dominique Gœuriot, Christelle Guerret-Piecourt, Denyse Juvé, Daniel Tréheux, et al.. Electron Beam Charging of Insulators with Surface Layer and Leakage Currents. Journal of Applied Physics, 2008, 103 (6), pp.064110. 10.1063/1.2890427 . hal-00281702

\section{HAL Id: hal-00281702 https://hal.science/hal-00281702}

Submitted on 23 May 2008

HAL is a multi-disciplinary open access archive for the deposit and dissemination of scientific research documents, whether they are published or not. The documents may come from teaching and research institutions in France or abroad, or from public or private research centers.
L'archive ouverte pluridisciplinaire HAL, est destinée au dépôt et à la diffusion de documents scientifiques de niveau recherche, publiés ou non, émanant des établissements d'enseignement et de recherche français ou étrangers, des laboratoires publics ou privés. 


\section{Electron Beam Charging of Insulators with Surface Layer and Leakage Currents}

N. Cornet and D. Goeuriot

Centre Sciences des Matériaux et des Structures, Ecole Nationale Supérieure des Mines, 158 cours Fauriel, F - 42023 Saint-Etienne cedex 2, France

C. Guerret-Piécourt, D. Juvé and D. Tréheux

Laboratoire de Tribologie et Dynamique des Systemes, UMR-CNRS 5513,

Ecole Centrale de Lyon, 36 avenue Guy de Collongue, F - 69134 Ecully cedex, France

M. Touzin

Laboratoire de Structure et Propriétés de l'Etat Solide-UMR-CNRS 8008,

Université des Sciences et Technologies de Lille, Bât C6, F-59655 Villeneuve d'Ascq cedex, France

H.-J. Fitting (a)

Physics Department, University of Rostock, Universitätsplatz 3, D - 18051 Rostock, Germany

Keywords: Insulators, Alumina, Silica, Electrical charging, Surface conductivity

PACS: 72.20.-i, 72.80.sk, 61.82.ms, 73.25.+i, 41.20.Cv, 79,20.Hx 


\section{Abstract}

The electron beam induced selfconsistent charge transport in layered insulators (here bulk alumina covered by a thin silica layer) is described by means of an electron-hole flightdrift model FDM and an iterative computer simulation. Ballistic secondary electrons and holes, their attenuation and drift, as well as their recombination, trapping, and detrapping are included. Thermal and field-enhanced detrapping are described by the Poole-Frenkel effect. Furthermore, an additional surface layer with a modified electric surface conductivity is included which describes the surface leakage currents and will lead to particular charge incorporation at the interface between the surface layer and the bulk substrate.

As a main result the time dependent secondary electron emission rate $\sigma(t)$ and the spatial distributions of currents $j(x, t)$, charges $\rho(x, t)$, field $F(x, t)$, and potential $V(x, t)$ are obtained. For bulk full insulating samples, the time-dependent distributions approach the final stationary state with $j(x, t)=$ const $=0$ and $\sigma=1$. In case of a measurable surface leakage current the steady stationary state is reached for $\sigma<1$. First measurements are extended to the sample current measurement including instationary components of charge incorporation and polarization as well as dc-components of leakage currents.

(a) Corresponding author:

Hans-Joachim Fitting

Physics Department, University of Rostock

D - 188051 Rostock

Germany

EMail: hans-joachim.fitting@uni-rostock.de

Tel: (+49)-381-498 6760, Fax: (+49)-381-498 6802 


\section{Introduction}

For numerous industrial applications, the ongoing miniaturization is the key point for future development ${ }^{1}$. For instance, the scaling down of electronic devices results in a constant decrease of the involved dielectric thickness leading to various problems of physical limits such as high leakage currents or breakdown phenomena ${ }^{2}$. A second example is the mass improvement of space shuttle or the miniaturization of automotive components like the reduction of size of the sparkplug to save on energetic resources while maintaining the breakdown strength ${ }^{3}$. The use of a modified surface layer or a thin film deposition is a classical solution to reach the targeted thickness or mass reduction while avoiding the problems mentioned above. In the case of complementary metal oxide semiconductor (CMOS) devices materials with higher dielectric constant (higher than that of $\mathrm{SiO}_{2}$ ) are used in order to reduce of the gate thickness ${ }^{2}$. For the dielectric strength or resistance to breakdown, one has used also encapsulation by thin films of the solar arrays by insulating coverslides ${ }^{4}$. In the case of size reduction of sparkplug with no loss of the dielectric strength, several surface treatments of the alumina material can be considered : (i) laser or heat treatments that allow to produce pore-free, crack-free, homogenous and harder surface than untreated surfaces ${ }^{5}$, (ii) coating with quasi-metallic layer or silica layer ${ }^{6,7}$, or (iii) doping or implantation with various ions $^{6,8}$. However the presence of these surface layers modifies the electrical charging of the whole sample. For example, in case of electronic devices X-ray photoelectron spectroscopy (XPS) is usually applied to characterize thin dielectric layers but mostly being affected by presence of an overlayer. Particularly the electrical charging of the substrate covered by an overlayer has retained the attention of several teams employing XPS characterization ${ }^{9,10}$. The electrical charging of spacecraft engines in space plasma environment can be also di- 
rectly affected by the presence of the coverslide. Finally, measurements of surface charge and secondary emission of coated or doped alumina have shown that substantial differences in the secondary electron emission and the total electron yield are due to minor changes in surface finish or modification ${ }^{6,8}$.

For a better understanding of these phenomena of charge transport and secondary electron emission, a physical model and a computer simulation will be set up in the present paper. Indeed, thanks to a flight-drift model (FDM) of injected electrons and holes in insulators and an iterative computer simulation, measurements of the charge injection during electron beam irradiation and understanding of the selfconsistent charge transport in bulk insulating samples is possible ${ }^{11,12}$. In Ref. 12 three types of non-conductive samples have been considered: A - the insulating bulk sample with an open surface to the vacuum, B the bulk sample with a positive ion-covered surface as it is given in environmental secondary electron microscopy (ESEM) under a certain gas pressure (some Torr) and gas ionization ${ }^{13,14}$, and $\mathrm{C}$ - the conducting and grounded surface coated by a metal or carbon layer in order to prevent charging of the bulk insulator.

The aim of the present work is to show the influence of a surface layer on the electron and hole injection, drift, and trapping, on the secondary electron emission, and on the spatial charging. For this reason a special Effective Layer Method (ELM) will be introduced to describe the electron scattering and straggling in a layered target. Moreover, the top surface layer will be characterized by surface leakage currents. As an example and application the particular case of a silica $\mathrm{SiO}_{2}$ surface layer deposited on an alumina $\mathrm{Al}_{2} \mathrm{O}_{3}$ substrate will be considered by simulation of the selfconsistent charge transport as well as by measurement of the polarization and surface leakage currents and the charge storage dynamics. 


\section{Theoretical Background}

The strong charging of insulators under electron beam irradiation has been well known, at least, since Malter 1936 discovered the anomalous high secondary electron emission (SEE) and long-lasting electron post-emission from $\mathrm{MgO}$ layers ${ }^{15}$. A strong positive charging due to the emission of secondary electrons (SE) from the surface-near regions is responsible for that selfconsistent field-enhanced SEE. On the other hand, the deeper injection of primary electrons (PE) will produce an electron surplus within the bulk of an insulator. The respective charge $\rho(x)$ and field $\boldsymbol{F}(x)$ distributions maintain the selfconsistent charge transport and the SEE emission.

An approach for a first estimation is based on the dynamic double layer model (DDLM) in which the phenomenon is brought to the simplified case of two layers of opposite charge. Complete solutions of the respective equations were achieved by Melchinger et al. ${ }^{16}$ and J. Cazaux ${ }^{17}$ developed an effective approach of the SEE evolution in insulating samples using this DDLM.

The first comprehensive Monte Carlo calculations of the self-consistent charging were made by Vicario et $a l .{ }^{18}$, Ganachaud et $a l .{ }^{19}$ and Renoud et al. ${ }^{20,21}$. Of course, these calculations are very complex because of the deal with the full simulation of primary electron straggling as well as with the generation and transport of secondary electrons and holes in the selfconsistent field. However, the decisive advantage of the full Monte-Carlo simulation is the 3-dimensional description of the charging process with the lateral charge spreading in case of point-like electron beam injection by a very small beam focus.

Of course, a planar 1-dimensional self-consistent model will approach validity if the electron beam diameter is much larger than the maximum electron penetration depth $R\left(E_{0}\right)$. 
Unambiguously, this is fulfilled in scanning electron microscopes (SEM) with a slightly defocused beam. Thus the 1-dimensional simulation can be applied to 3-dimensional description of the sample potential in a SEM chamber ${ }^{11,12}$. Early attempts with the planar selfconsistent charging simulation were performed by our co-author (HJF) already in $1978^{22,23}$, later on improved for insulating layers on conducting substrate in Ref. 24 and for bulk insulating materials in Ref. 11 and 12. These authors use field-dependent attenuation lengths $\lambda(F)$ for the ballistic transport of electrons and holes which had been found experimentally by means of electron beam induced currents (EBIC) measurements ${ }^{25}$ and had been verified by Monte Carlo calculations ${ }^{26-29}$.

The present paper will use the more comprehensive and realistic flight-drift model (FDM) for electrons and holes as already demonstrated in Ref. 12 . There the ballistic flight of excited electrons and holes is followed by their drift and respective recombination and/or trapping in shallow and deep traps. Moreover, the electron and hole scattering and transport should be considered in a heterogeneous layered insulator sample. Thus the numerical and experimental results will be presented in particular for bulk alumina $\left(\mathrm{Al}_{2} \mathrm{O}_{3}\right)$ covered by a thin surface layer of silica $\left(\mathrm{SiO}_{2}\right)$. Nevertheless, these simulations can be easily adapted to any layered insulator system using the relevant material data. 


\section{A. Electron beam injection and excitation - the effective layer method (ELM)}

The problem of electron beam charge injection in a heterogeneous layered target is demonstrated in Fig. 1. Incident electrons (so-called primary electrons PE) with initial energy $E_{0}$ and current density $j_{0}$ penetrate the insulator target up to the maximum range $R\left(E_{0}\right)$. The injection of primary electrons (PE) and their creation of secondary electrons $(\mathrm{SE})$ and holes $(\mathrm{H})$ are very similar for alumina $\mathrm{Al}_{2} \mathrm{O}_{3}$ and silica $\mathrm{SiO}_{2}$ as we have described already in Refs. 30 - 32 based on empirical results of the electron penetration into and through thin films, see the "film-bulk method" in Ref. 31, 32. By means of this method the resulting PE current density in dependence on the target depth $x$ and the PE initial energy $E_{0}$ was found:

$$
j_{\mathrm{PE}}\left(x, E_{0}\right)=j_{0}\left(1-\eta_{\mathrm{B}}\right) \exp \left[-4.605\left(\frac{x}{R\left(E_{0}, Z\right)}\right)^{p_{(Z)}}\right],
$$

with $j_{0}$ as impinging $\mathrm{PE}$ current density and the material parameters for $\mathrm{SiO}_{2}$ and $\mathrm{Al}_{2} \mathrm{O}_{3}$ : $\eta_{\mathrm{B}} \approx 0.2$ the backscattering coefficient, $p=2$ the transmission exponent. An appropriate formula for the maximum range $R\left(E_{0}\right)$ of electrons reached by $1 \%$ of $\mathrm{PE}$ in dependence on their initial energy $E_{0}$ was deduced from experimental data, ${ }^{30-38}$, see Fig. 2 and presented in Ref. 38 for $\mathrm{SiO}_{2}$ and $\mathrm{Al}_{2} \mathrm{O}_{3}$ in the relevant energy region $1<E_{0} \leq 30 \mathrm{keV}$ with:

$$
\begin{aligned}
& R_{\mathrm{SiO}_{2}}=33.7\left(E_{0} / \mathrm{keV}\right)^{1.55} \\
& R_{\mathrm{Al}_{2} \mathrm{O}_{3}}=28.7\left(E_{0} / \mathrm{keV}\right)^{1.55}
\end{aligned}
$$

where $\mathrm{R}$ is given in $\mathrm{nm}$, and the electron beam energy $E_{0}$ should be inserted in $\mathrm{keV}$. Electron penetration curves according to Eq. (1) and (2) are presented already in Refs. 12, 32, and 38. For an exact charge balance within the insulating target the deposited, i.e. absorbed PE's in the depth $x$ have to be taken into account too. They present an additional negative electron charge, added to the excited secondary electrons (SE), which are generated in parity 
to the positive holes $(\mathrm{H})$. The PE absorption density, or better said PE deposition function $g_{\mathrm{PE}}$, is given by the negative first derivative of the PE penetration current density of Eq. (1), see Ref. 12:

$$
j_{0} \cdot g_{P E}=9.21 \cdot \frac{x}{R^{2}} \cdot j_{P E}\left(x, E_{0}\right)
$$

Of course, these exhausted and deposited PE will continue their motion like created common SE and should be added finally to the SE generation function $g_{\mathrm{SE}}$ of Eq. (4) as will be done in Eq. (9).

On the other hand, the spatial SE generation rate $g_{S E}\left(x, E_{0}\right)$ excited by PE is proportional to the spatial energy loss $d E / d x$ of the impinging and straggling primary electrons (PE). This energy transfer has to be divided by the SE excitation energy $E_{i}$. From Ref. 39 and the given dielectric electron energy loss function $\operatorname{Im}(-1 / \epsilon)$ for $\mathrm{SiO}_{2}$ we recognize energy losses up to $90 \mathrm{eV}$ for valence band electron excitation, i.e. excitation of secondary electrons. The most probable loss amounts $24 \mathrm{eV}$ and the mean loss even will exceed the 3-fold energy gap width $3 E_{g} \cong 27 \mathrm{eV}$. Moreover, the SE creation energy $E_{i}$ is increasing with the PE energy $E_{0}$ as we could show directly by film-bulk measurements ${ }^{40}$. Thus our application with a relatively high PE energy $E_{0}=20 \mathrm{keV}$ will justify $E_{i}=\left(3 E_{g}+1\right) \mathrm{eV}$ as used for semiconductors too ${ }^{41}$. As we have already shown in Refs. 11, 12, and 38, for the both insulators $\mathrm{SiO}_{2}$ and $\mathrm{Al}_{2} \mathrm{O}_{3}$ with the same band gap of $E_{g}=9 \mathrm{eV}$ and nearly the same SE generation energy of $E_{i} \approx 28 \mathrm{eV}$, we may write the spatial SE generation rate $g_{\mathrm{SE}}$ in both $\mathrm{SiO}_{2}$ and $\mathrm{Al}_{2} \mathrm{O}_{3}$ targets in the form of a semi-empirical equation:

$$
g_{S E}\left(x, E_{0}\right)=g_{\mathrm{SH}}\left(x, E_{0}\right)=\frac{1.544}{R\left(E_{0}\right)} \frac{E_{0}}{E_{i}} \exp \left[-7.5\left(\frac{x}{R}-0.3\right)^{2}\right]
$$

Of course, secondary electrons $\left(g_{S E}\right)$ and holes $\left(g_{S H}\right)$ are created in parity presenting a Gaussian distribution with the maximum shifted by $0.3 R$ from the surface into the target volume, 
as shown in Fig. 3.

Of course, the energy transfer function $d E / d x$ in a heterogeneous layered target is stepwise inhomogeneous, and there is no simple mathematical expression to describe it. Therefore we have proposed an Effective Layer Model (ELM) in Ref. 38 based on effective layers $d_{\text {eff }}$ substituting all the previous top material layers $i-1$ above the layer $i$ by an effective layer thickness $d_{i-1}^{\text {eff }}$ of the following material $Z_{i}$. In order to determine the effective layer thickness $d_{1}^{\text {eff }}$ of only one covering top material $Z_{1}$ we will compare equal transmission rates in both materials: $\eta_{T}\left(d_{1}, Z_{1}, E_{0}\right)=\eta_{\mathrm{T}}\left(d_{1}^{\text {eff }}, Z_{2}, E_{0}\right)$. With electron transmission rates in dependence on reduced depths according to Eq.(1) we get:

$$
\eta_{T}=\exp \left[-4.605 \cdot\left(\frac{d_{1}}{R_{1}}\right)^{p_{1}}\right]=\exp \left[-4.605 \cdot\left(\frac{d_{1}^{\text {eff }}}{R_{2}}\right)^{p_{2}}\right]
$$

and a power relation for the effective layer $d_{1}^{\text {eff }}$ replacing the first (top) material:

$$
d_{1}^{\text {eff }}=\left(\frac{d_{1}}{R_{\mathrm{SiO}_{2}}}\right)^{p_{1} / p_{2} \approx 1} \cdot R_{\mathrm{Al}_{2} \mathrm{O}_{3}}
$$

can be deduced from Fig. 1. This effective layer $d_{1}^{\text {eff }}$ of the top material is inserted into the depth-related function of the transmission rate Eq. (1):

$$
\eta_{\mathrm{T}}\left(x, E_{0}\right)=\exp \left[-4.605\left(\frac{x-d_{1}+d_{1}^{\text {eff }}}{R_{\mathrm{Al}_{2} \mathrm{O}_{3}}\left(E_{0}\right)}\right)^{2}\right]
$$

$d_{1}^{\text {eff }}$ replaces the top material of real thickness $d_{1}$ by the effective layer $d_{1}^{\text {eff }}$ of the substrate, whereas $x$ is the absolute sample depth within the layered target but now located already in the bottom substrate, see Fig. 1.

The similar substitution we may perform for the $\mathrm{SE}$ generation function in the bottom $\mathrm{Al}_{2} \mathrm{O}_{3}$ substrate, modifying Eq. (4):

$$
g_{\mathrm{SE}}\left(x, E_{0}\right)=\frac{1.544}{R_{\mathrm{Al}_{2} \mathrm{O}_{3}}\left(E_{0}\right)} \frac{E_{0}}{E_{i}} \exp \left[-7.5\left(\frac{x-d_{1}+d_{1}^{\text {eff }}}{R_{\mathrm{Al}_{2} \mathrm{O}_{3}}\left(E_{0}\right)}-0.3\right)^{2}\right]
$$


The respective excitation functions for a $\mathrm{SiO}_{2}-\mathrm{Al}_{2} \mathrm{O}_{3}$ layer system with a top layer $\mathrm{SiO}_{2}$ of thickness $d_{1}=0 ; 0.25 ; 0.5 ; 0.75 ;$ and $1.0 \cdot R_{\mathrm{SiO}_{2}}$ is presented in Fig. 3 . Because of a shorter maximum range $R\left(E_{0}\right)$ in $\mathrm{Al}_{2} \mathrm{O}_{3}$ (see Eq. (2a)-(2b)) the excitation density in this bottom substrate material is higher (more concentrated) than in the top layer material $\mathrm{SiO}_{2}$, indicated by a certain step at the chosen interface $d_{1}$. As already mentioned, inner secondary electrons and holes are generated in parity, i.e. their generation rates are equal: $g_{\mathrm{SE}} \equiv g_{\mathrm{SH}}$, as it will be used in the following part.

\section{B. Ballistic currents of excited electrons and holes}

Assuming an isotropic SE generation, one half of the created SE: $1 / 2 j_{0} g_{S E}\left(x, E_{0}\right) \Delta x$ will move into the bulk sample, i.e. in the direction towards the sample support, called transmission $(\mathrm{T})$, and the other half towards the sample surface, called reverse direction or remission $(\mathrm{R})$. Then the respective continuity equation in 1-dimensional form for ballistic SE or hole current densities in transmission $(\mathrm{T}$ ) direction towards the sample substrate (holder) or in reverse or remission $(\mathrm{R})$ direction towards the surface can be written ${ }^{11,12}$ :

$$
\begin{aligned}
& \quad j_{\mathrm{BET}}^{\mathrm{BER}}(x)=\left[j_{\mathrm{BET}}^{\mathrm{BER}}(x \pm \Delta x)+\frac{1}{2} j_{0}\left[g_{\mathrm{SE}}\left(x, E_{0}\right)+g_{\mathrm{PE}}\left(x, E_{0}\right)\right] \Delta x\right] \underbrace{\exp \left[-\frac{\Delta x}{\lambda_{\mathrm{E}, 0} \exp \left( \pm \beta_{\mathrm{E}} F\right)}\right]}_{W_{\mathrm{EF}}} \\
& \text { and for holes, respectively: }
\end{aligned}
$$

$$
\underbrace{j_{\mathrm{BHT}}^{\mathrm{BHR}}(x)=\left[j_{\mathrm{BHT}}^{\mathrm{BHR}}(x \pm \Delta x)+\frac{1}{2} j_{0} g_{\mathrm{SE}}\left(x, E_{0}\right) \cdot \Delta x\right] \underbrace{\exp \left[-\frac{\Delta x}{\lambda_{\mathrm{H}, 0} \exp \left(\mp \beta_{\mathrm{H}} F\right)}\right]}_{\text {generation }}}_{\text {convection }}
$$

The first term in the brackets presents the convection part from the adjacent cell $\Delta x$; the second one the generation of inner SE: $\left(g_{\mathrm{SE}}+g_{\mathrm{PE}}\right)$ or holes $\left(g_{\mathrm{SH}}=g_{\mathrm{SE}}\right)$ followed by the 
ballistic attenuation probability $W_{\mathrm{EF}}(x)$ and $W_{\mathrm{HF}}(x)$ of the charge carriers over the small distance $\Delta x$ in the target depth $x$. These attenuation probabilities have been described comprehensively in Refs. 25, 11, 12, 22, 23. Note that in Eq. (9) we have added the exhausted and deposited PE with $g_{\mathrm{PE}}$ to the generated SE with $g_{\mathrm{SE}}$.

The part $j_{\mathrm{BER}}(x=0)$ of ballistic SE moving towards the surface and being reflected at the surface barrier $(x=0)$ presents the initial current density $j_{\mathrm{BET}}(x=0)$ of transmitting SE into the sample volume towards the bulk :

$$
j_{\mathrm{BET}}(x=0)=\sqrt{\frac{\chi}{\bar{E}_{\mathrm{SE}}}} j_{\mathrm{BER}}(x=0) \simeq 0.3 j_{\mathrm{BER}}(x=0)
$$

where $\chi=0.9 \mathrm{eV}$ is the surface electron affinity and $\bar{E}_{\mathrm{SE}}$ the mean kinetic energy of SE in the conduction band of $\mathrm{Al}_{2} \mathrm{O}_{3}$ or $\mathrm{SiO}_{2}$, see Refs. 42, 11 and 12. The part of SE non-reflected at the surface is emitted into the vacuum presenting the external current $j_{\text {SEE }}$ of secondary electrons:

$$
j_{\mathrm{SEE}}=\left(1-\sqrt{\frac{\chi}{\bar{E}_{\mathrm{SE}}}}\right) j_{\mathrm{BER}}(x=0) \simeq 0.7 j_{\mathrm{BER}}(x=0)
$$

where the forefactor is deduced from reflection and refraction at the surface barrier ${ }^{42}$. Thus the rate of "true" SE is given by: $\delta=j_{\mathrm{SEE}} / j_{0}$.

Moreover, this rate of SEE may be reduced additionally by retarding field effects, i.e. if the surface potential $V_{0}(x=0)$ becomes more positive than the first grid electrode with a potential $V_{\mathrm{G}}$. For $V_{0}>V_{\mathrm{G}}$ we get a retarded SEE current density:

$$
j_{\mathrm{SEE}}^{*}=j_{\mathrm{SEE}} \exp \left(-\frac{V_{0}-V_{\mathrm{G}}}{5 \text { Volt }}\right)
$$

as we have demonstrated in Refs. 11 and 12.

Finally, the rate of total SEE, i.e. the sum of backscattered and material released electrons is obtained by: 


$$
\sigma(t)=\eta_{\mathrm{B}}+\delta(t)=1+\frac{j(x=0, t)}{j_{0}}
$$

where $j(x=0)$ is the total current over the surface barrier ${ }^{11,12}$.

\section{Drift currents of attenuated electrons and holes}

The Flight-Drift Model (FDM) with the scattering and straggling of primary electrons (PE), their excitation of secondary electrons (SE) and holes (SH), their ballistic flight as ballistic electrons $(\mathrm{BE})$ and holes $(\mathrm{BH})$, respectively, their attenuation and drift as drifting electrons (DE) and holes (DH) in selfconsistent fields, followed by recombination and/or trapping and detrapping in localized states (traps) is presented schematically in Fig. 4 and has been described comprehensively in our previous paper ${ }^{12}$. All these processes are included in the following Eq. (15) for drifting electrons (DE) in reverse (R) direction towards the surface and transmission (T) directions into the sample volume (bulk) : 


$$
\begin{aligned}
& j_{\mathrm{DET}}^{\mathrm{DER}}(x)=\left\{j_{\mathrm{DET}}^{\mathrm{DER}}(x \pm \Delta x)+\quad\left[j_{\mathrm{BER}}(x)\left[1-W_{\mathrm{EFR}}(x)\right]+j_{\mathrm{BET}}(x)\left[1-W_{\mathrm{EFT}}(x)\right]+\right.\right. \\
& \text { convection generation by ballistic attenuation } \\
& \left.\left.+\quad \varrho_{\mathrm{E} 1}(x) W_{\mathrm{E} 1 \mathrm{PF}}+\varrho_{\mathrm{E} 2}(x) W_{\mathrm{E} 2 \mathrm{PF}}\right] \times F_{\mathrm{E}}(x)\right\} \times \\
& \text { detrapping by Poole-Frenkel effect } \\
& \times \underbrace{\exp \left[-\left(N_{1}-\frac{\varrho_{E 1}}{e_{0}}\right) S_{\mathrm{E} 1} \Delta x\right]}_{W_{\mathrm{E} 1}} \cdot \underbrace{\exp \left[-\left(N_{2}-\frac{\varrho_{E 2}}{e_{0}}\right) S_{\mathrm{E} 2} \Delta x\right]}_{W_{\mathrm{E} 2}} \times \\
& \text { trapping in shallow }{ }^{(1)} \text { and deep }{ }^{(2)} \text { states } \\
& \times \underbrace{\exp \left[-\frac{\varrho_{H 1}}{e_{0}} S_{\mathrm{EH} 1} \Delta x\right]}_{W_{\mathrm{EH} 1}} \cdot \underbrace{\exp \left[-\frac{\varrho_{H 2}}{e_{0}} S_{\mathrm{EH} 2} \Delta x\right]}_{W_{\mathrm{EH} 2}}
\end{aligned}
$$

recombination with holes

Here the first convection term describes incoming and outgoing drifting electrons in the depth element $\Delta x$; the second generation term presents the sources of drifting electrons by attenuated (exhausted) ballistic electrons; the third (detrapping) term is given by the Poole-Frenkel release of electrons from traps, presenting also a source of drifting electrons. The field factor $F_{E}$ describes the anisotropy of all generated drifting electrons (DE) in the electric field $F$. Finally, as electron drains we see the trapping and recombination terms with trap concentrations $N$ and actual charges $\varrho$ as well as the respective cross sections $S$, all as presented in Fig. 4. Of course, the current density equation $j j_{\mathrm{DHT}}^{\mathrm{DHR}}$ for drifting holes (DH) looks adequate with the respective trapping parameters of holes, as already described in Ref. 12.

Note that the field direction factors $F_{\mathrm{E}}$ and $F_{\mathrm{H}}$ are acting to all "initial" drift electrons (DE) and holes (DH), as shown in Eq. (15). 
This field direction factor $F_{\mathrm{E}}$ for electrons is explained in Fig. 5 as a result of Monte Carlo calculations and given in analytic form by means of Eqs. (16a) and (16b) presented in Fig. 6:

$$
\begin{aligned}
& F_{E}=\frac{1}{2}-\frac{1}{2} \tanh \frac{F}{F_{E 0}} \\
& F_{H}=\frac{1}{2}+\frac{1}{2} \tanh \frac{F}{F_{H 0}} .
\end{aligned}
$$

Further on, the Poole-Frenkel release ${ }^{43,44}$ of charges from traps is given by Eq. (17):

$$
W_{\mathrm{EPF}}^{\mathrm{HPF}}=f_{\mathrm{E}}^{\mathrm{H}} \exp \left[-\frac{E_{\mathrm{E}}^{\mathrm{H}}-\Delta E_{\mathrm{PF}}}{k T}\right]
$$

for electrons $(\mathrm{E})$ and holes $(\mathrm{H})$, respectively. This enhanced charge release from traps is due to a trap barrier lowering $\Delta E_{\mathrm{PF}}$ by an electric field $F^{44}$ :

$$
\Delta E_{\mathrm{PF}}=2 \frac{e^{3 / 2}}{\left(4 \pi \varepsilon_{0} \varepsilon_{r}\right)^{1 / 2}} F^{1 / 2}=\beta_{\mathrm{PF}} F^{1 / 2}
$$

For the relevant dielectric and insulating materials alumina and silica with respective dielectric permittivities $\varepsilon_{r}$ we get the trap barrier lowering:

$$
\frac{\Delta E_{\mathrm{PF}}}{\mathrm{eV}}=10^{4}\left(\frac{e}{\pi \varepsilon_{0} \varepsilon_{r}}\right)^{1 / 2} F_{\frac{\mathrm{MV}}{\mathrm{cm}}}^{1 / 2} \simeq\left\{\begin{array}{lll}
0.24 \mathrm{eV} \cdot F_{\frac{\mathrm{MV}}{\mathrm{cm}}}^{1 / 2} & \text { for } \mathrm{Al}_{2} \mathrm{O}_{3} ; & \varepsilon_{r}=10 \\
0.38 \mathrm{eV} \cdot F_{\frac{\mathrm{MV}}{\mathrm{cm}}}^{1 / 2} & \text { for } \mathrm{SiO}_{2} ; & \varepsilon_{r}=4
\end{array}\right.
$$

Finally, as given in Eqs. (15) - (19) for electrons (E), the same procedure has to be performed for holes $(\mathrm{H})$ too and the resulting charges will be counted from the balance of trapping and detrapping: $\varrho(x, t)=-\varrho_{\mathrm{E} 1}-\varrho_{\mathrm{E} 2}+\varrho_{\mathrm{H} 1}+\varrho_{\mathrm{H} 2}$.

On the other hand, we may account the charges and the fields from current fluctuations (divergences) too:

$$
-\frac{\partial}{\partial x} j(x, t)=\frac{\partial \varrho(x, t)}{\partial t}=\epsilon_{0} \epsilon_{r} \frac{\partial}{\partial t} \frac{\partial}{\partial x} F(x, t)
$$

as it has been already described more detailed in Ref. 12. However, in case of heterogeneous 
samples a jump of field strengths should be considered at the interface $d_{1}$ of the top layer to the substrate (see Fig. 1):

$$
F_{2}\left(d_{1}+\right)=\frac{\varepsilon_{1}}{\varepsilon_{2}} F_{1}\left(d_{1}-\right)
$$

when integrating the field strengths over the charges, see Eq. (20) and Ref. 12.

\section{Electron and hole trapping and detrapping by Poole-Frenkel effect}

In this part let us check the validity and reasonability of the Poole-Frenkel trappingdetrapping mechanisms. We may describe the trapping and detrapping processes by firstorder kinetics. Thus an incident current density $j$ leads to an actual trap occupation rate $n_{T}(t)$ with time $t$ :

$$
d n_{T}=+\frac{j}{e_{0}}\left(N-n_{T}\right) \cdot S \cdot d t-n_{T} f \exp \left(-\frac{E_{T}-\Delta E_{\mathrm{PF}}}{k T}\right) \cdot d t
$$

where the second term means the Poole-Frenkel release of trapped charges (detrapping). $N$ is the existing trap concentration, $S$ the capture cross section, $f$ an "attempt of escape frequency factor", shortly called pre-exponential "frequency factor", and $\Delta E_{\mathrm{PF}}$ the lowering of the thermal activation energy $E_{\mathrm{T}}$ by an electric field $F$, i.e. the Poole-Frenkel effect, as already described by Eqs. (17) - (19).

In the following we have tested the trapping and Poole-Frenkel release mechanism by means of time-dependent filling and detrapping of the balance Eq. (22) and its iterative integration $t=t+\Delta t$. Thus we get the partial filling rates as presented in Fig. 7 . From these calculations we may deduce an appropriate frequency factor dependence on the trap activation energy, see Fig. 8:

$$
\log f=4+5 E_{\mathrm{T}}(\mathrm{eV})
$$


where the frequency factor $f$ is given in $\mathrm{s}^{-1}$ and the activation energy $E_{\mathrm{T}}$ in $\mathrm{eV}$.

Thus very shallow traps like small polarons possess only little thermal activation energies $E_{t} \approx(0.1-0.5) \mathrm{eV}$ with relatively low frequency factors of $f \approx\left(10^{4}-10^{6}\right) \mathrm{s}^{-1}$ whereas deeply trapped electrons with activation energies $E_{t} \approx 2 \mathrm{eV}$ will be released at higher temperatures $T \approx 500{ }^{\circ} \mathrm{C}$ with an almost highest frequency factor of $f \approx 10^{14} \mathrm{~s}^{-1}$. This is in agreement with the experiences of thermally stimulated processes, e.g. of Chen ${ }^{42}$ and Refs. 46 - 48.

\section{E. Surface leakage current}

Insulating devices are not only characterized by their bulk volume electrical resistance but also by their surface leakage conductivity. In our experiments ${ }^{11,12}$ of polarization displacement current measurements we often observed a dc-current component to the metallic sample support (holder) as a considerable background to the highly instationary and fast decaying polarization current $i_{p}$, see Fig. 1. Because we could exclude real bulk conduction currents $i_{c}$ only tertiary scattered electrons TE from the SEM chamber walls or surface leakage currents could be taken into account, see Fig. 1 in Ref. 11. The first ones we could exclude by full screening of the sample ${ }^{49}$ and the metallic sample holder (support electrode), thus the latter ones, the surface leakage currents should be responsible for such a dc sample current towards the sample support electrode. Moreover, we have measured them by surface ring electrodes ${ }^{50}$.

In the present paper we want to insert these surface leakage currents $i_{S}$ into our selfconsistent charging and current balances. As we have described all kinds of currents $i$ by their current densities $j$ related to the spot area of electron irradiation and the incident PE current density $j_{0}$ we also will relate the surface leakage current to this irradiated area and current densities 
describing it by $j_{S}$.

Our ansatz will include proportionality to the surface potential $V_{0}$ and indirect to the surface radius $R_{S}$, further on, to a surface conductivity $\sigma_{0}$ modified by a Poole-Frenkel charge release from shallow surface states with small thermal activation energy $E_{S}$ (hopping):

$$
j_{S}=\frac{V_{0}}{R_{S}} \sigma_{0} \exp \left[-\frac{E_{S}-\Delta E_{\mathrm{PF}}}{k T}\right]
$$

The first factor $V_{0} / R_{S}$ presents a medium surface field strength of about tens of $\mathrm{kV} / \mathrm{cm}$; the surface conductivity could be estimated to $\sigma_{0}=1.25 \cdot 10^{-7} \mathrm{~A} / \mathrm{Vcm}$ or $\mathrm{S} / \mathrm{cm}$; whereas the surface trap energy was chosen with $E_{S}=(0.1-0.3) \mathrm{eV}$. These parameters were estimated from first surface current measurements of Ref. 50 and data of thermal trap spectroscopy ${ }^{46}$, respectively.

The resulting surface currents $j_{S}$ are presented in Fig. 9 in dependence on the surface potential $V_{0}$. Of course the current magnitude is increasing with the sample temperature $T$ as well as with the surface trap barrier lowering as a function of the surface field strength $\Delta E_{\mathrm{PF}}\left(V_{0} / R_{S}\right)$ as given with Eqs. (18) and (19). However, the surface field strength $F_{S}$ with tens of $\mathrm{kV} / \mathrm{cm}$ are relatively small with respect to internal bulk field strengths $F(x)$ and so the surface current $j_{S}$ will be controlled mostly by the temperature $T$. 


\section{Simulation of Selfconsistent Charging}

The general computation scheme has been presented already in Ref. 12. In the present work, the scattering interaction mechanisms, according to the Eqs. (5) - (10) and (16a) (24) and as described in the previous chapter, have been installed additionally. The first simulations for layered targets were performed for $3 \mathrm{~mm}$ bulk $\mathrm{Al}_{2} \mathrm{O}_{3}$ samples covered by a 1 $\mu \mathrm{m} \mathrm{SiO}_{2}$ surface layer, see Fig. 1. The necessary material parameters of the substrate $\mathrm{Al}_{2} \mathrm{O}_{3}$ are given in Tab. 1 of Ref. 11; the data of the surface layer $\mathrm{SiO}_{2}$ mostly in Ref. 24. Other parameters are described already in the respective text parts of this paper. Furthermore, comprehensive Monte Carlo calculations of secondary electron generation, scattering, and emission are made and well illustrated in Ref. 28. There one may find $\mathrm{SiO}_{2}$ material parameters presented in a table too, as well as SE energy distributions, attenuation and escape depths.

In order to protect the samples from thermal irradiation effects and material modifications, we used in our measurements as well as simulations a slightly "defocused" electron beam of $1 \mathrm{nA}$ impinging an area of $\left(100 \mu \mathrm{m}^{2}\right)$ leading to a primary electron current density of $j_{0}=10^{-5} \mathrm{~A} / \mathrm{cm}^{2}=10 \mu \mathrm{A} / \mathrm{cm}^{2}$. This planar geometry of about $100 \mu \mathrm{m}$ beam width (diameter) much greater than $R=3 \mu$ m electron maximum penetration depth maintains the assumption of the planar 1-dimensional target model. So we may use mean ballistic attenuation lengths for secondary electrons $\lambda_{E, 0}=5 \mathrm{~nm}$, for holes $\lambda_{H, 0}=2 \mathrm{~nm}$ and respective attenuation field factors $\beta_{E}=4.6 \mathrm{~cm} / \mathrm{MV}$ and $\beta_{H}=0.8 \mathrm{~cm} / \mathrm{MV}$ in accordance with Refs. 11,12 and $22-29$.

More difficult is the selection of appropriate electron and hole trap concentrations $N, H$, their capture cross sections $S_{E}, S_{H}$, their thermal activation energies $E_{E}, E_{H}$, and recombi- 
nation cross sections $S_{E H}$ and $S_{H E}$, as given in Fig. 4. For our first calculations presented here we choose the following data, estimated from Refs. 46 - 51: shallow trap concentrations $N_{E 1}=N_{H 1}=10^{20} \mathrm{~cm}^{-3}$ corresponding to high concentrations of selftrapping by small polaron formation; their capture cross sections $S_{E 1}=S_{H 1}=10^{-13} \mathrm{~cm}^{2}$ and thermal activation energies $E_{E 1}=E_{H 1}=0.2 \mathrm{eV}$. Of course, the deeper traps possess less concentration: $N_{E 2}=N_{H 2}=10^{16} \mathrm{~cm}^{-3}, S_{E 2}=S_{H 2}=10^{-13} \mathrm{~cm}^{2}$, and $E_{E 2}=E_{H 2}=2 \mathrm{eV}$. The Coulomb-attractive recombination can be described by a relatively high cross section $S_{E H}=S_{H E}=10^{-13} \mathrm{~cm}^{2}$. We should mention here that a more diverse trap parameter selection and optimization will be done when more direct comparison with experimental data will be available. In this context also especial interface traps should be introduced at the boundary $d_{1}$ between the top layer and the substrate.

\section{A. Saturation of SE rate and surface potential}

First of all we want to check the total SE emission rate $\sigma=\eta+\delta$ of backscattered $(\eta)$ and true secondary electrons $(\delta)$ released from the target material. For bulk insulating samples and no electrical conduction to the support this rate $\sigma$ should approach the value "one" in stationary saturation state, $\sigma(t) \rightarrow 1$, i.e. currents of injected primary electrons $(\mathrm{PE}) j_{0}$ and emitted backscattered and secondary electrons $j_{\mathrm{SE}}$ compensate each other, see Fig. 1.

In Fig. 10 (top) we see that this steady stationary state is reached after $(20-50) \mathrm{ms}$ electron beam injection with $E_{0}=20 \mathrm{keV}$ and $j_{0}=10 \mu \mathrm{A} / \mathrm{cm}^{2}$ in case of a sufficiently low temperature, here at about room temperature $T=300 \mathrm{~K}$. It means that for this temperature the supposed surface traps with thermal activation energy $E_{S} \cong 0.2 \mathrm{eV}$ are not yet activated and the surface charges remain still localized. Increasing the sample temperature 
$T$ to 500 and $1000 \mathrm{~K}$ we observe a lower (less 1 ) saturation value of $\sigma(t)$ with an indication of a surface leakage current $j_{S}>0$ due to the increasing mobility of the surface charges in the higher mean surface field $V_{0} / R_{S}$ as given by Eq. (24) in the part II-E.

This increasing negative surface potential $V_{0}(t)$ is presented in the lower part of Fig. 10. There the maximum negative value $V_{0} \approx-15 \mathrm{kV}$ is reached already after $t=17 \mathrm{~ms}$ injection but then a slight decrease due to surface charge release and surface leakage current $j_{S}(t)$ is observed leading finally also to a saturation state with a surface potential of about $V_{0}(t>70 \mathrm{~ms}) \approx 12.5 \mathrm{kV}$ for a high temperature of $T=1000 \mathrm{~K}$. Obviously, this behavior of the both experimentally accessible quantities, the SE rate $\sigma$ and the surface potential $V_{0}$, offers the possibility to compare and characterize insulators with respect to their electrical features.

\section{B. Spatial distributions of currents, charges, and field}

The peculiarity of the layered sample with a surface layer of thickness $d_{1}$ on a bulk substrate is the interface between both in the depth $d_{1}$ as shown in Fig. 1. Thus in Fig. 2 the SE-hole excitation densities are demonstrated in such a heterogeneous layered sample. Consequently, the ballistic electron and hole currents show an inhomogeneity at $d_{1}$ too, as demonstrated in Fig. 11. Within the more dense material $\mathrm{Al}_{2} \mathrm{O}_{3}$ the spatial concentration of electrons and holes is higher than in $\mathrm{SiO}_{2}$ leading to a jump of currents across the interface at $d_{1}$.

Zooming on the interface we observe a "hysteresis" of the ballistic currents in reverse (R) and transmission (T) direction, Fig. 12 (top). Below we find the respective diffusion currents but still in nearly field-free conditions after an injection time of only $1 \mathrm{~ms}$. Whereas the "hysteresis" of ballistic charge carriers is sharply bended at the interface $d_{1}$, the diffusion 
currents show smeared and spread junctions across the interface. But the drains and sources of diffusion currents are regions of charge accumulation and depletion, respectively, as given by Eqs. (15) and (20). Consequently, a bipolar minus-plus spatial charge distribution is built up at the interface $d_{1}$, as to be seen in Fig. 12 (lower part). Because the electric field in this region is negative (see below in Fig. 12) the diffusion electrons in reverse direction $j_{\text {DER }}$ are prevailing all the other current components producing finally the negative charge accumulation on the left hand side of the interface. Consequently more holes are trapped on the right hand side of the interface forming a positive charge concentration. The initial (1 ms) electric field distribution $F(x)$ in Fig. 12 (bottom) shows the expected jump at the interface $d_{1}$ due to the different electrical permittivities $\epsilon_{1} / \epsilon_{2}$ according to Eq. (21). Furthermore, the field $F$ appears negative and represents the charge distribution $\varrho(x)$ discussed above according to Eq. (20).

With ongoing electron beam injection the internal current density $j(x, t)$ will be flattened and finally approaching the value zero over the full depth $x: j(x, \infty) \rightarrow 0$. This corresponds to the steady stationary state $\sigma=1$. Thereby the irradiated volume is shrinked due to the electron beam retarding by the strong negatively charged surface of nearly $-15 \mathrm{kV}$ for room temperature $T=300 \mathrm{~K}$ or $-12.5 \mathrm{kV}$ for $T=1000 \mathrm{~K}$. Both distributions are presented on the left and right hand side of Fig. 13, respectively. This negative charging and retarding leads to an electron beam landing energy of only

$$
E_{0}^{\prime}=E_{0}+e V_{0}
$$

diminished by the negative surface potential $e V_{0}$. Thus the primary electron (PE) maximum range and excitation depth is diminished too by means of Eqs. (2), (4), and (8). The respective charge distributions in Fig. 13 (middle) show a typical plus-minus-plus-minus 
quadro-polarity as already described in Refs. 11 and 12. The reason for that is the electric field distribution in plus-minus bipolarity as to be seen in the bottom part of Fig. 13.

In general, the escape and emission of SE into the vacuum produces a positive charge and a positive field beneath the surface. The positive field even leads to a so-called field-enhanced secondary electron emission. Thus drifting electrons will be swept to the left hand side in reverse direction towards the surface whereas holes are swept to the right in transmission direction into the bulk forming the successive region of minus-plus charge accumulation. In deeper regions the field changes the sign because of totally prevailing negative charges due to $\sigma<1$, and becomes negative. So drifting electrons are swept in transmission direction into the volume; even they may exceed the maximum range $\mathrm{R}$ of injected primary electrons and form the deep negative volume charge. Thus we get the plus-minus-plus-minus charge distribution in direction of increasing target depth $x$. But here in the layered sample an additional bi-polar local charge minus-plus is build up at the interface $d_{1}$ as described already above in context with Fig. 12. This alternating charge is growing still during the irradiation as can be seen in Fig. 13 (middle). Of course, a higher temperature, e.g. $T=1000 \mathrm{~K}$ (Fig. 13, right) will diminish the incorporated charges, first by their higher mobility and increasing drift and compensation (recombination), secondly by an increasing surface leakage current and the removal of electrons lowering the overall negative charge and the negative surface potential $V_{0}$, see Fig. 10 .

\section{Sample Current Measurement}

According to Fig. 1 we may construct a current measurement arrangement as given in Fig. 14. In order to measure the mostly instationary sample current $i_{\mathrm{SC}}(t)$ the support 
electrode must be shielded thoroughly to prevent stray electrons (tertiary electrons TE) from the microscope chamber walls and lens pole pieces to be collected too. They would produce an artificial dc component of $i_{\mathrm{SC}}$ what may be interpreted wrongly as an insulator real conduction current $i_{\mathrm{C}}$. However, the shield should collect and ground the surface leakage current $i_{\mathrm{S}}$. Thus we get the sample current $i_{\mathrm{SC}}$ as the primary electron (PE) beam injection current $i_{0}$, but diminished by the total secondary electron rate $\sigma=\eta_{\mathrm{BE}}+\delta_{\mathrm{SE}}$ and the surface current $i_{\mathrm{S}}$ :

$$
i_{\mathrm{SC}}(t)=[1-\sigma(t)] i_{0}-i_{\mathrm{S}}(t)
$$

The surface leakage current $i_{\mathrm{S}}(t)$ will depend on the setup of the negative surface potential $V_{0}(t)$ as given with Eq. (24). Hence $V_{0}(t)$ approaches a saturation value, $i_{\mathrm{S}}(t)$ will approach a constant value too. Further on, $\sigma(t)$ draws near unit with time (see Fig. 10) thus the sample current $i_{\mathrm{SC}}$ will decrease nearly to zero. The remaining dc-component of $i_{\mathrm{SC}}$ should be associated to $i_{\mathrm{S}}$.

In our measurements the instationary sample current $i_{\mathrm{SC}}(t)$ was recorded by a storage oscilloscope. The sample itself was a non-covered bulk alumina ceramic disc of $17 \mathrm{~mm}$ diameter and $2.7 \mathrm{~mm}$ thickness. The aperture of the metallic shield amounts $10 \mathrm{~mm}$ in diameter. More experimental details are described in Ref. 49.

In Fig. 15 experimental and simulated sample currents $i_{\mathrm{S}}(t)$ are compared. Clearly we observe the instationary behavior as described above as well as a small, but constant surface leakage current after irradiation of about $30 \mathrm{~ms}$. The beam injection was performed with $E_{0}=30 \mathrm{keV}$ and $j_{0}=30 \mu \mathrm{A} / \mathrm{cm}^{2}$ over $100 \mathrm{~ms}$ on a fresh spot position of the sample. Thus the beam current density is 3 times higher than in our simulations of Fig. 10 and the saturation $\sigma \rightarrow 0$ is reached faster, already at about $10 \mathrm{~ms}$ indicating a sublinear function 
of charging velocity vs. electron beam density $j_{0}$. It may be explained by the binary processes of electron-hole recombination and subsequently higher order of charge recombination kinetics.

We may state a still sufficient agreement of the simulated and the measured sample currents $i_{\mathrm{SC}}(t)$, although, a certain deviation in the pulse shape becomes obvious. Probably, this is due to a more rapid charge trapping behavior in reality than we have used in our calculations. It will be a forthcoming task to optimize the simulation with respect to experimental data. In this context we give preference to the real-time measurements of the here presented instationary sample current measurement $i_{\mathrm{SC}}(t)$ and the direct surface potential measurement $e V_{0}(t)=E_{0}-E_{0}^{\prime}$ according to Eq. (25) by means of the shifted high energy x-ray bremsstrahlung (BS) edge $E_{0}^{\prime}$, the so-called Duane-Hunt limit, as we have demonstrated in Ref. 11. A direct imaging of charge distributions by low vacuum scanning electron microscopy LV-SEM has been presented recently ${ }^{51}$ and is based on field-enhanced conductivity.

\section{Conclusions}

Electron beam irradiation and charge injection associated by selfconsistent charge transport in insulating samples are described by means of an electron-hole flight-drift model (FDM) implemented by an iterative computer simulation. Ballistic scattering and transport of secondary electrons and holes is followed by electron and hole drift, their possible recombination and/or trapping in shallow and deep traps. Furthermore a detrapping by the temperature- and field-dependent Poole-Frenkel-effect becomes possible allowing even a charge hopping transport. In this context a special surface layer has been installed to 
investigate the effect of surface leakage current, also following the Poole-Frenkel trappingdetrapping mechanism.

As a main result the spatial distributions of currents $j(x, t)$, charges $\rho(x, t)$, electric field $F(x, t)$, and potential $V(x, t)$ are obtained in a selfconsistent procedure as well as the time dependent secondary electron emission rate $\sigma(t)$ and surface potential $V_{0}(t)$ both experimentally accessible. For bulk full insulating samples the above quoted time-dependent distributions approach the final stationary state under the condition $j(x, t)=$ const $=0$ and $\sigma=1$. In case of remarkable surface leakage current $i_{\mathrm{S}}$ the steady stationary final state is obtained with $\sigma<1$. The difference is collected with the surface current $i_{\mathrm{S}}$ and can be measured by a respective ring electrode. For a high beam energy $E_{0}=20 \mathrm{keV}$ and room temperature $T=300 \mathrm{~K}$ a high negative surface potential $V_{0}=-14 \mathrm{kV}$ is obtained, diminished to $-12.5 \mathrm{kV}$ with increasing temperature up to $T<1000 \mathrm{~K}$. Because of this high negative surface potential the electron beam is decellerated down to a real landing energy $E_{0}^{\prime}=E_{0}+e V_{0} \approx(6-7.5) \mathrm{keV} \rightarrow\left(E_{0}^{I I}\right)$ near to the second sigma-unit value $\sigma\left(E_{0}^{I I}\right)=1$.

In spite of a negative surface potential $V_{0}$ the charge beneath the surface is positive due to the favored SE escape. But, generally we obtain a plus-minus-plus-minus spatial charge distribution with prevailing minus parts within the bulk insulator produced by a bipolar field: a positive field near the surface and a negative one in the remaining bulk. Thus, due to drift processes we obtain two opposite charge separations leading to the quadro-polarized charge structure across the sample depth.

The experimental method of stationary-instationary sample current $i_{\mathrm{SC}}(t)$ measurements allows us to measure the instationary charge displacement (incorporation) and polarization current $i_{p}$ as well as the surface leakage current $i_{S}$, or occasionally, the volume conduction current $i_{c}$ as a function of temperature. The experimental results are still in a sufficient 
agreement with our selfconsistent charge transport simulation. It offers the opportunity to investigate and to characterize insulating materials with respect to their quality, their electrical behavior, and radiation resistance. 


\section{References}

1 M. G. D. Geers, V. Kouznetsova and W. A. M. Brekelmans, Journal of Electronic Packaging, 127, 255 (2005)

2 R. G. Vitchev, J. J. Pireaux, T. Conard, H. Bender, J. Wolstenholme and C. Defranoux, Appl. Surf. Sci. 235, 21 (2004)

3 M. O’Neill, J. Howell, L. Lollar, C. Carrington, N. Suzuki, M. Piszczor, D. Hoppe, M. Eskenazi, D. Aiken, M. Fulton, H. Brandhorst, M. Schuller and A. J. McDanal Acta Astronautica, 59, 157 (2006)

4 D. C. Ferguson and G. B. Hillard, NASA reports, TP-2003-212287 (2003)

5 D. Triantafyllidis, L. Li and F. H. Stott, Thin Solid Films 453-454, 76 (2004)

6 J. M. Elizondo, K. Meredith and N. Lapetina, IEEE Transactions on Plasma Science 30, $1955(2002)$

7 L. F. Valandro, A. Della Bona, M. A. Bottino and M. P. Neisser, Journal of Prosthetic Dentistry 93, 253 (2005)

8 Y. J. Lei and D. Q. Xiao, IEEE Transactions on Dielectrics and Electrical Insulation 13, $93(2006)$

9 M. Dubey, I. Gouzman, S. L. Bernasek and J. Schwartz, Langmuir 22, 4649 (2006)

${ }^{10}$ G. Vereecke and P. G. Rouxhet, Surface and Interface Ananlysis 26, 490 (1998)

${ }^{11}$ X. Meyza, D. Goeuriot, C. Guerret-Piécourt, D. Tréheux and H.-J. Fitting, J. Appl. Phys. 94, 5384 (2003)

${ }^{12}$ M. Touzin, D. Goeuriot, C. Guerret-Piécourt, D. Juvé, D. Tréheux and H.-J. Fitting, J. Appl. Phys. 99, 114110 (2006) 
M. Toth, M. R. Phillips, B. L. Thiel, A. M. Donald,

J. Appl. Phys. 91, 4479 and 4492 (2002)

14 M. Toth, B. L. Thiel, A. M. Donald, Ultramicroscopy 94, 71 (2003)

15 L. Malter, Phys. Rev. 49, 478 (1936)

16 A. Melchinger, S. Hofmann, J. Appl. Phys. 78, 6624 (1995)

17 J. Cazaux, J. Appl. Phys. 85, 1137 (1999)

E. Vicario, N. Rosenberg, R. Renoud, Surface and Interface Analysis 22, 115 (1994)

19 J. P. Ganachaud, C. Attard, R. Renoud, Physica Status Solidi (b) 199, 175 and 455(1997)

20 R. Renoud, F. Mady, J. P. Ganachaud, J. Phys.: Condensed Matter 14, 231-247 (2002)

21 F. Mady, R. Renoud, C. Attard, J. Bigarré, J.-P. Ganachaud, P. Hourquebie,

Eur. Phys. J. Appl. Phys. 20, 41 (2002)

H.-J. Fitting, H. Glaefeke, W. Wild, M. Franke, W. Müller,

Experimentelle Technik der Physik (Berlin) 27, 13 (1979)

I. A. Glavatskikh, V. S. Kortov, H.-J. Fitting, J. Appl. Phys. 89, 440-448 (2001)

25 Th. Hingst, M. Hübner, R. Franz, Ch. Kuhr, H.-J. Fitting,

Microelectronic Engineering 24, 181 (1994)

26 H.-J. Fitting, J.-U. Friemann, Physica Status Solidi (a) 69, 349 (1982)

27 H.-J. Fitting, J. Boyde, Physica Status Solidi (a) 75, 137 (1983)

28

E. Schreiber, H.-J. Fitting,

J. Electron Spectroscopy \& Related Phenomena 124, 25 (2002)

29

H.-J. Fitting, E. Schreiber, I. A. Glavatskikh,

Microscopy \& Microanalysis (USA) 10, 764 (2004)

30

H.-J. Fitting, Physica Status Solidi 26, 525 (1974) 
A. von Czarnowski, J. Electron Spectroscopy \& Rel. Phenom., 159, 46 (2006)

J. Electron Spectroscopy \& Rel. Phenom., 119, 35 (2001)

H.-J. Fitting, H. Glaefeke, W. Wild, G. Neumann,

J. Phys. D: Appl. Phys. 9, 2499 (1976)

41 R. C. Alig, S. Bloom, Phys. Rev. Lett. 35, 1522 (1975)

Clarendon Press, Oxford, 1973

R. Chen, J. Appl. Phys. 40, 570 (1969)

G. Rudlof, J. Becherer, H. Glaefeke, Physica Status Solidi (a) 52, K137 (1979)

H.-J. Fitting, D. Hecht, Physica Status Solidi (a) 108, 265 (1988)

D. Hecht, H.-J. Fitting, Experimentelle Technik der Physik (Berlin) 39, 185 (1991)

M. Touzin, PhD thesis, Ecole Natinal Supérieure des Mines de St. Étienne, France, Dec. 2005. 
50 T. Temga, D. Juvé, D. Treheux, C. Guerret-Piécourt and C. Jardin, Nuclear Instruments and Methods in Physics Research, Section B: Beam Interactions with Materials and Atoms 245, 519 (2006)

51 M. Toth, R. Knowles, Appl. Phys. Lett. 90, 072905 (2007) 


\section{Captions of the Figures}

Fig. 1 Primary electron (PE) injection into a layered target with a surface layer $d_{1}$ and an overall sample thickness $D$; the interaction volume (hatched) is extended to the maximum electron range $R\left(E_{0}\right)$ with following currents: $i_{\mathrm{BE}}$ : backscattered electron, $i_{\mathrm{SE}}$ : secondary electrons, $i_{\mathrm{S}}$ : surface current, $i_{\mathrm{c}}:$ possible real conduction current, $i_{\mathrm{p}}$ : polarization displacement current.

Fig. 2 Maximum range relations $R\left(E_{0}\right)$ in insulators silica $\mathrm{SiO}_{2}$ and alumina $\mathrm{Al}_{2} \mathrm{O}_{3}$ obtained by different authors ${ }^{30-38}$. The special approaches Eqs. (2a) and (2b) for the SEM energy region 1-30 keV are obtained in Ref. 38.

Fig. 3 Heterogeneous energy deposition in layered insulator targets $\mathrm{SiO}_{2}$ on $\mathrm{Al}_{2} \mathrm{O}_{3}$ with different top $\mathrm{SiO}_{2}$ layer thicknesses: $d_{1}=0 ; 0.25 ; 0.5 ; 0.75 ;$ and $1.0 R_{\mathrm{SiO}_{2}}$; thus the top distribution corresponds to uncovered bulk $\mathrm{Al}_{2} \mathrm{O}_{3}$, the bottom one to full bulk $\mathrm{SiO}_{2}$.

Fig. 4 Scheme of the flight-drift model (FDM) including the excitation of ballistic electrons and holes, their flight and attenuation, followed by drift or diffusion, trapping, and/or recombination. Indicated are the respective trap parameters and cross sections.

Fig. 5 Angular distributions of electron diffusion and drift in $\mathrm{SiO}_{2}$ as obtained in Monte Carlo simulations of Ref. 26. 
Fig. 6 Field direction factors $F_{\mathrm{E}}$ and $F_{\mathrm{H}}$ of Eqs. (16a) and (16b) for anisotropic drift of electrons and holes in and against an electric field $F$, respectively.

Fig. 7 Trapping and detrapping rates $n_{\mathrm{T}}$ of charge carriers in localized states (traps) with concentration $N=10^{18} \mathrm{~cm}^{-3}$ and thermal activation energies $E_{\mathrm{T}}=0.3$ and $1.5 \mathrm{eV}$, respectively, according to Eq. (22). Respective frequency factors $f=10^{5}$ and $10^{11} \mathrm{~s}^{-1}$ were estimated according to Fig. 8 and Eq. (23).

Fig. 8 Detrapping frequency factor $f$ of charge release from traps with thermal activation energy $E_{\mathrm{T}}$, demonstrating the range from full to empty traps for two temperatures $T=300$ and $800 \mathrm{~K}$ according to Eq. (22) and Fig. 7, finally leading to Eq. (23).

Fig. 9 Surface current $j_{S}$ as a function of the surface potential $V_{0}$ and temperature $T$; thermal activation energy of surface traps $E_{S}=0.1 \mathrm{eV}$, surface radius $R_{S}=1 \mathrm{~cm}$.

Fig. 10 Total SE rate $\sigma(t)$ and surface potential $V_{0}$ as a function of irradiation time $t$ and sample temperature $T$; sample: $1 \mu \mathrm{m} \mathrm{SiO}_{2}$ layer on $3 \mathrm{~mm} \mathrm{Al}_{2} \mathrm{O}_{3}$; $E_{S}=0.2 \mathrm{eV} ; E_{0}=20 \mathrm{keV} ; j_{0}=10 \mu \mathrm{A} / \mathrm{cm}^{2}$. 
Fig. 11 Current density $j(x)$ of ballistic electrons (inner SE's) and holes in reverse and transmission direction within a layered target after $t=1 \mathrm{~ms}$ irradiation still in nearly field-free state; $E_{0}=20 \mathrm{keV} ; j_{0}=10 \mu \mathrm{A} / \mathrm{cm}^{2}$.

Fig. 12 Zoom of the $\mathrm{SiO}_{2}-\mathrm{Al}_{2} \mathrm{O}_{3}$ interface at $x=d_{1}=1 \mu \mathrm{m}$ from Fig. 11 with the spatial distributions of ballistic and diffusion electrons and holes, trapped charges, and electric field (from top to bottom) after $t=1 \mathrm{~ms}$ still in nearly field-free conditions.

Fig. 13 Development of spatial distribution with time $t$ at two temperatures $T=300$ and $1000 \mathrm{~K}$ within a layered target $\mathrm{SiO}_{2}-\mathrm{Al}_{2} \mathrm{O}_{3}$ : total internal current $j(x)$ (top), charge density $\rho(x)$ (middle), and electric field $F(x)$ (bottom); $E_{0}=20 \mathrm{keV}, j_{0}=10 \mu \mathrm{A} / \mathrm{cm}^{2}$.

Fig. 14 Sample shielding and arrangement for sample current $i_{\mathrm{SC}}$, surface current $i_{\mathrm{S}}$, and polarisation current $i_{\mathrm{p}}$ measurements according to Eq. (26).

Fig. 15 Simulated acc. Eq. (26) and experimental sample currents $i_{\mathrm{SC}}(t)$ as given in Fig. 14 with the instationary decreasing polarisation current $i_{\mathrm{p}}(t)$ and an increasing but then stationary surface current $i_{\mathrm{S}}(t)$. 


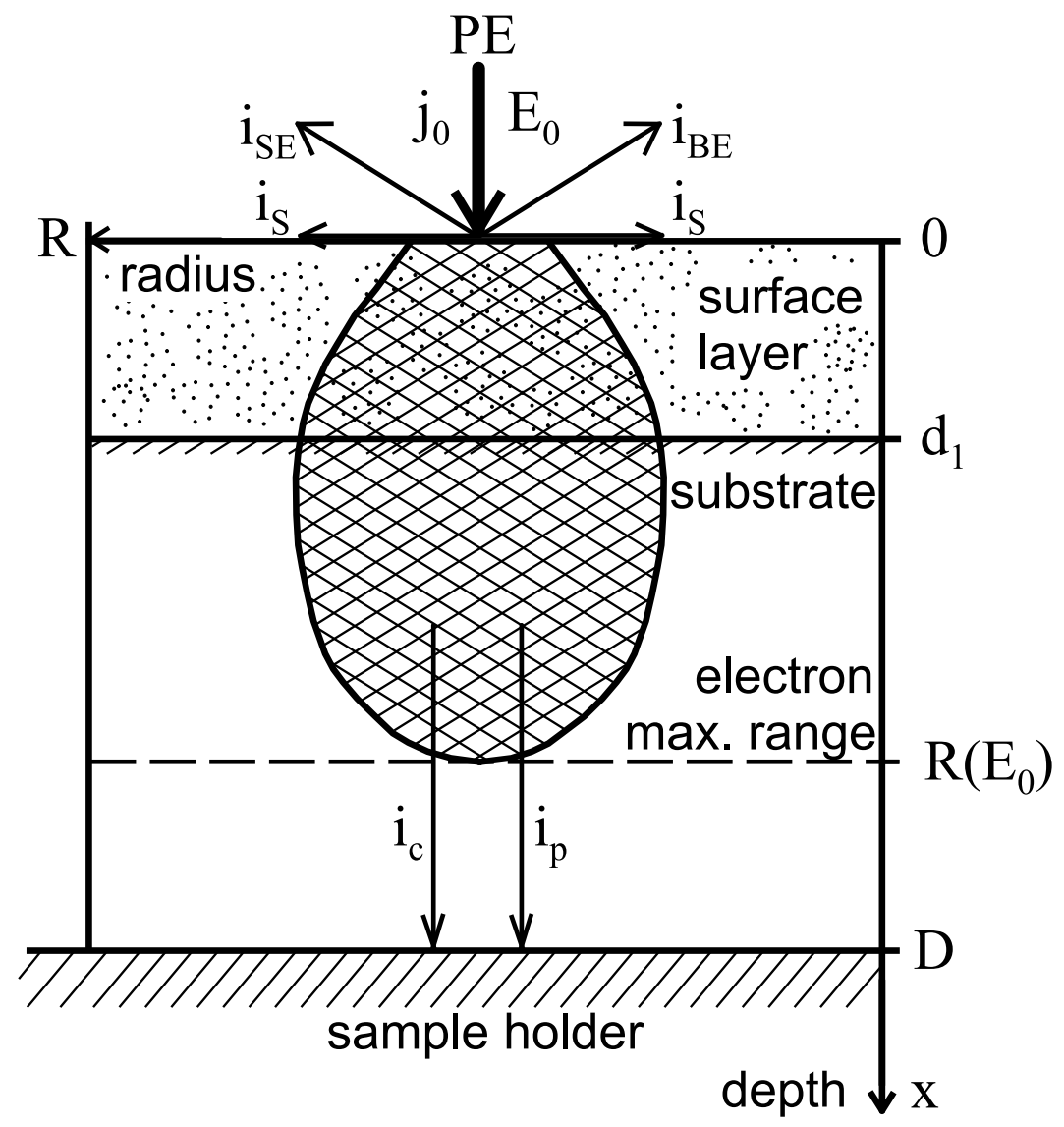

Fig. 1: 

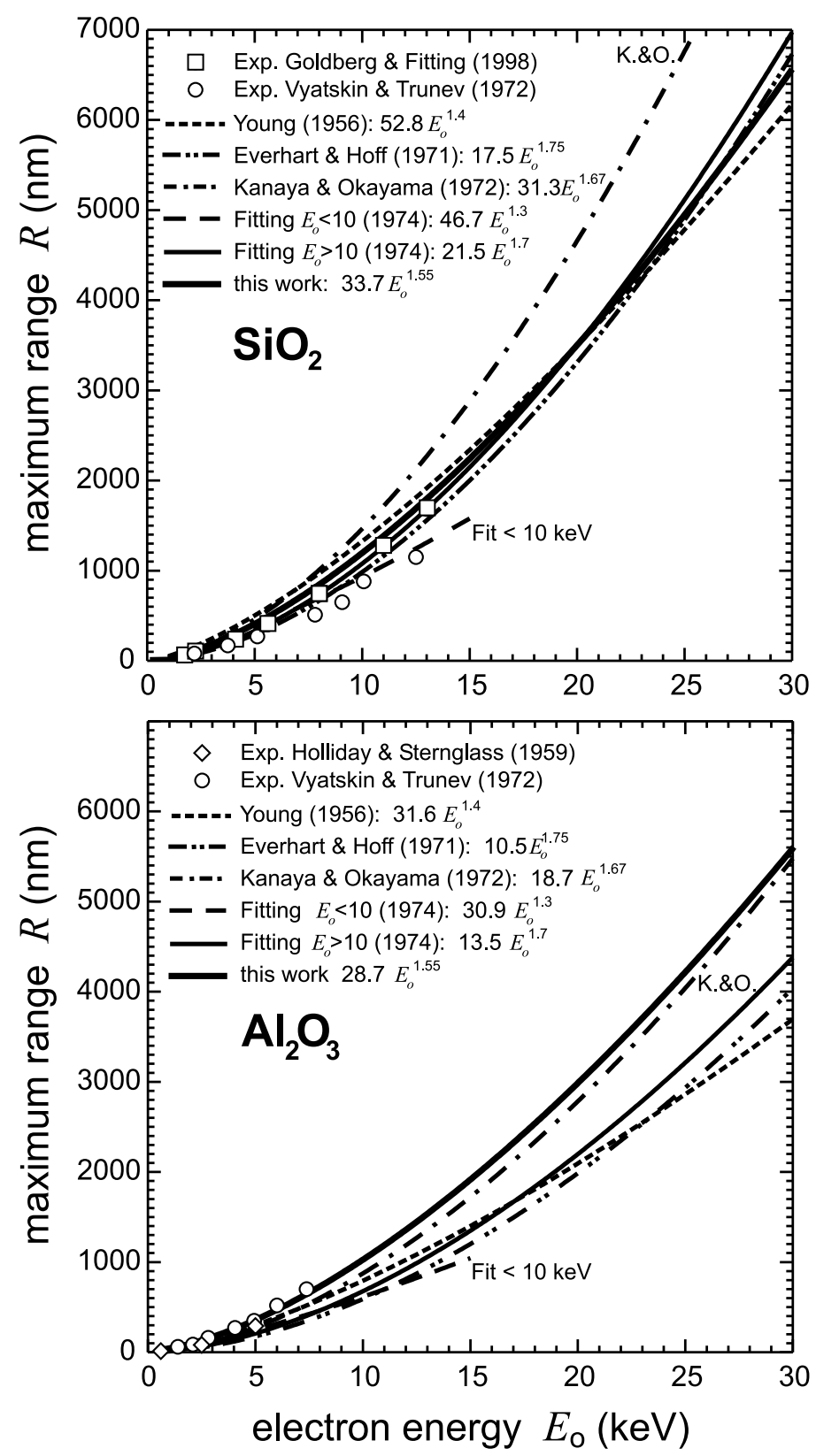

Fig. 2: 


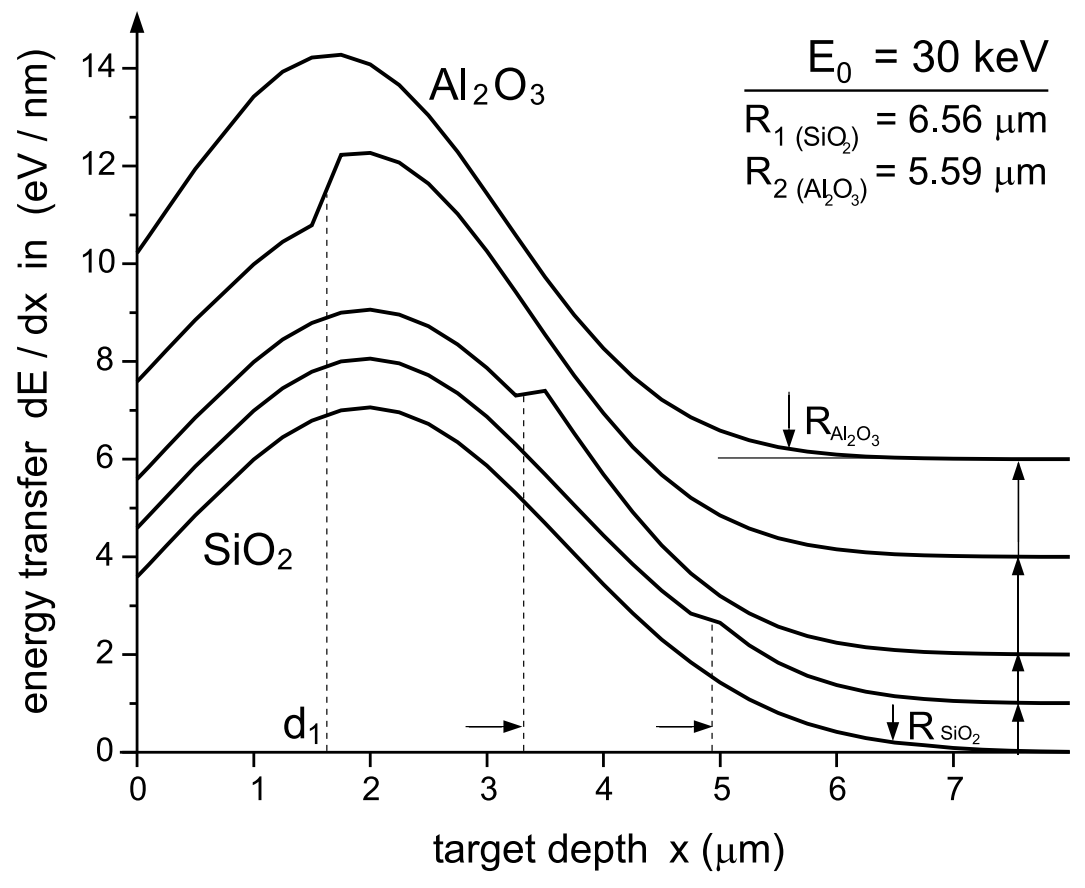

Fig. 3: 


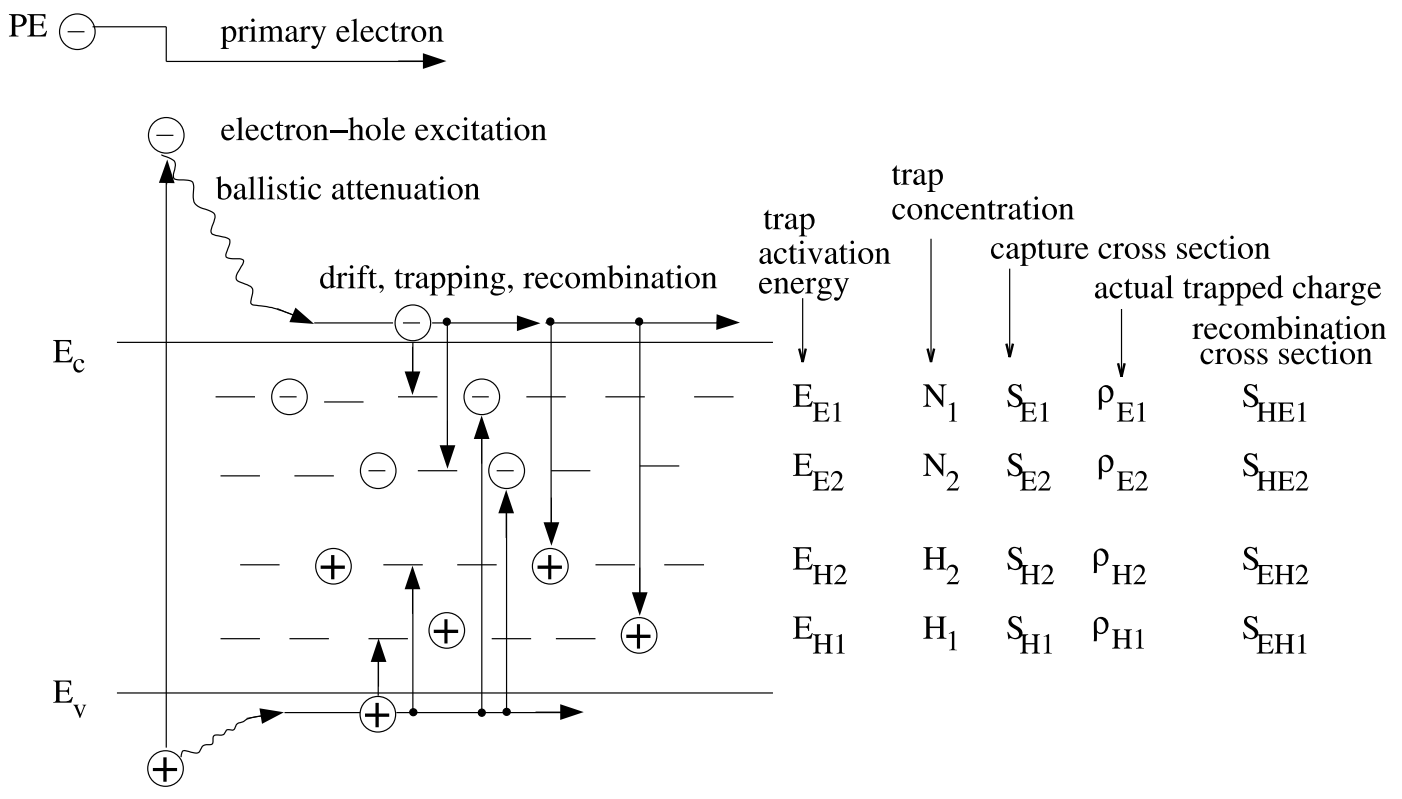

Fig. 4: 


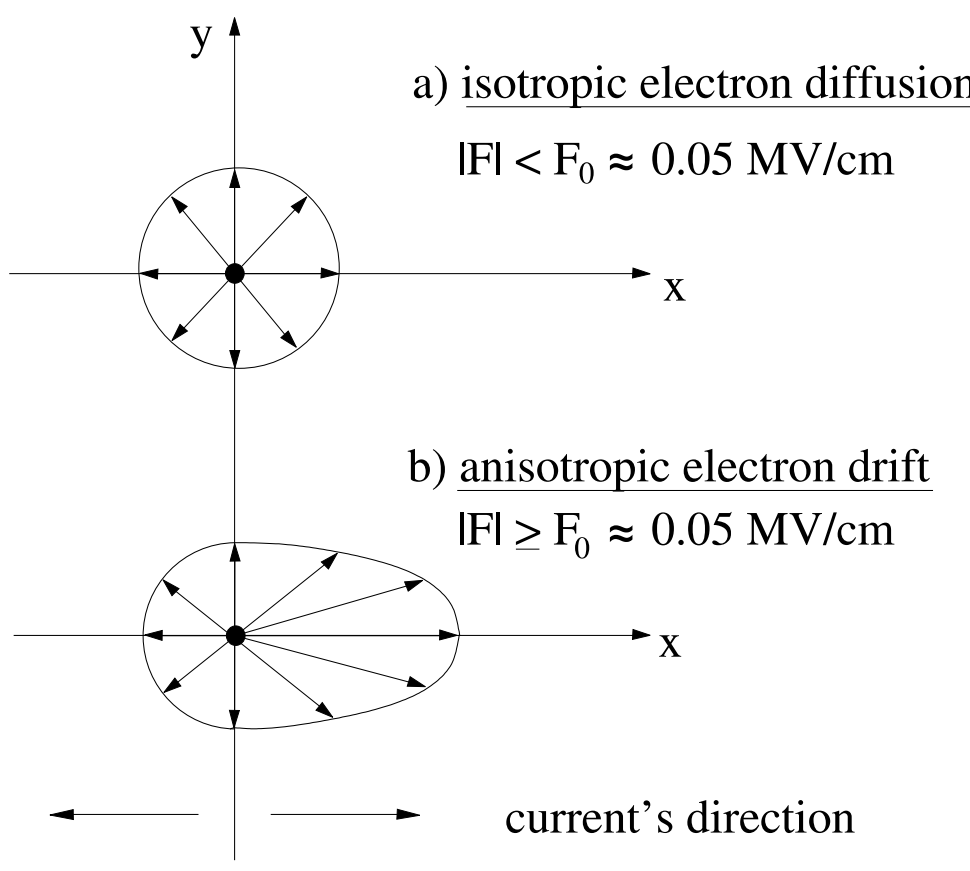

Fig. 5 


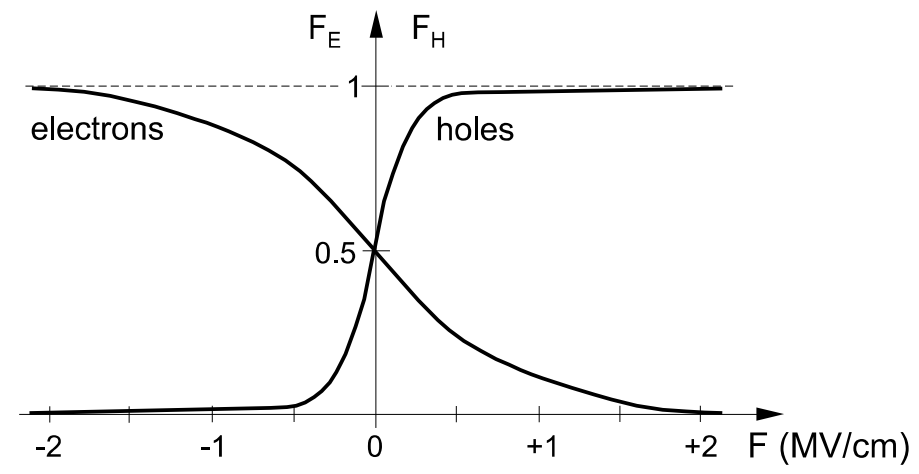

Fig. 6 

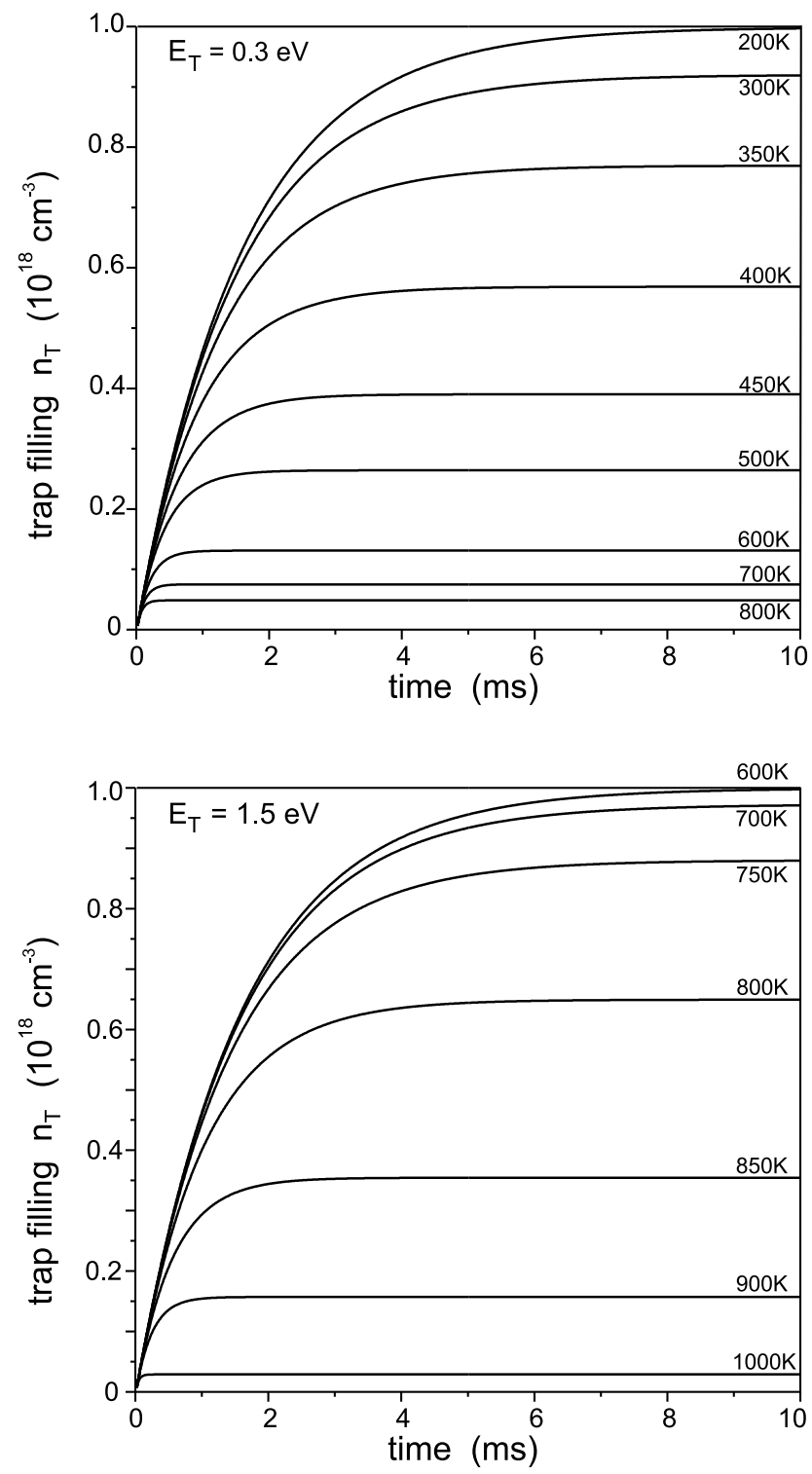

Fig. 7 


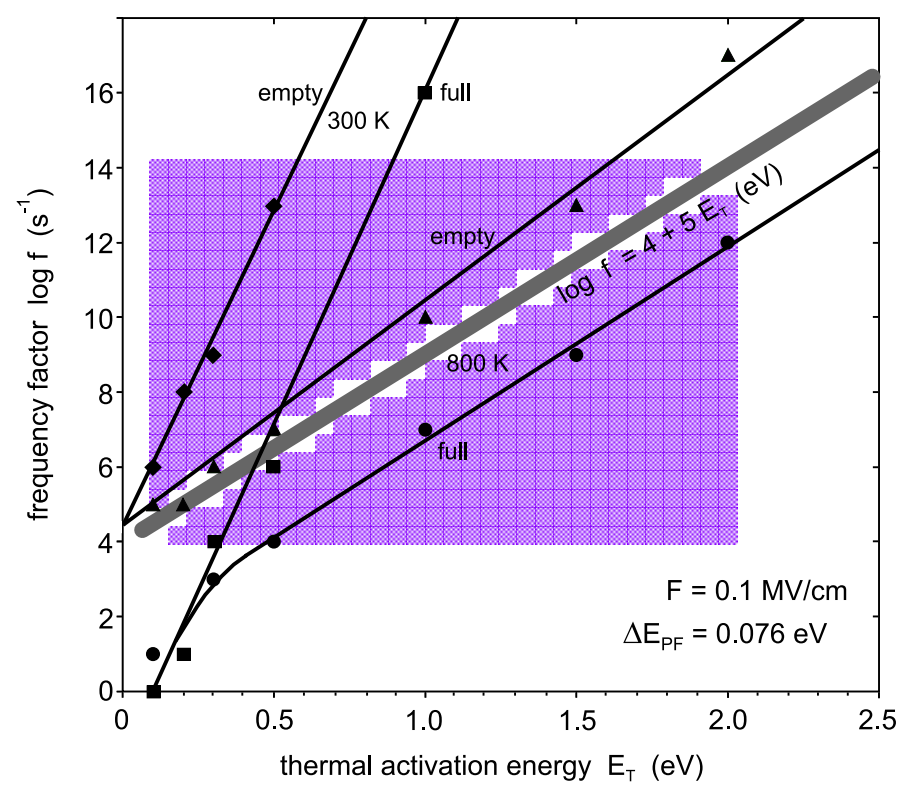

Fig. 8 


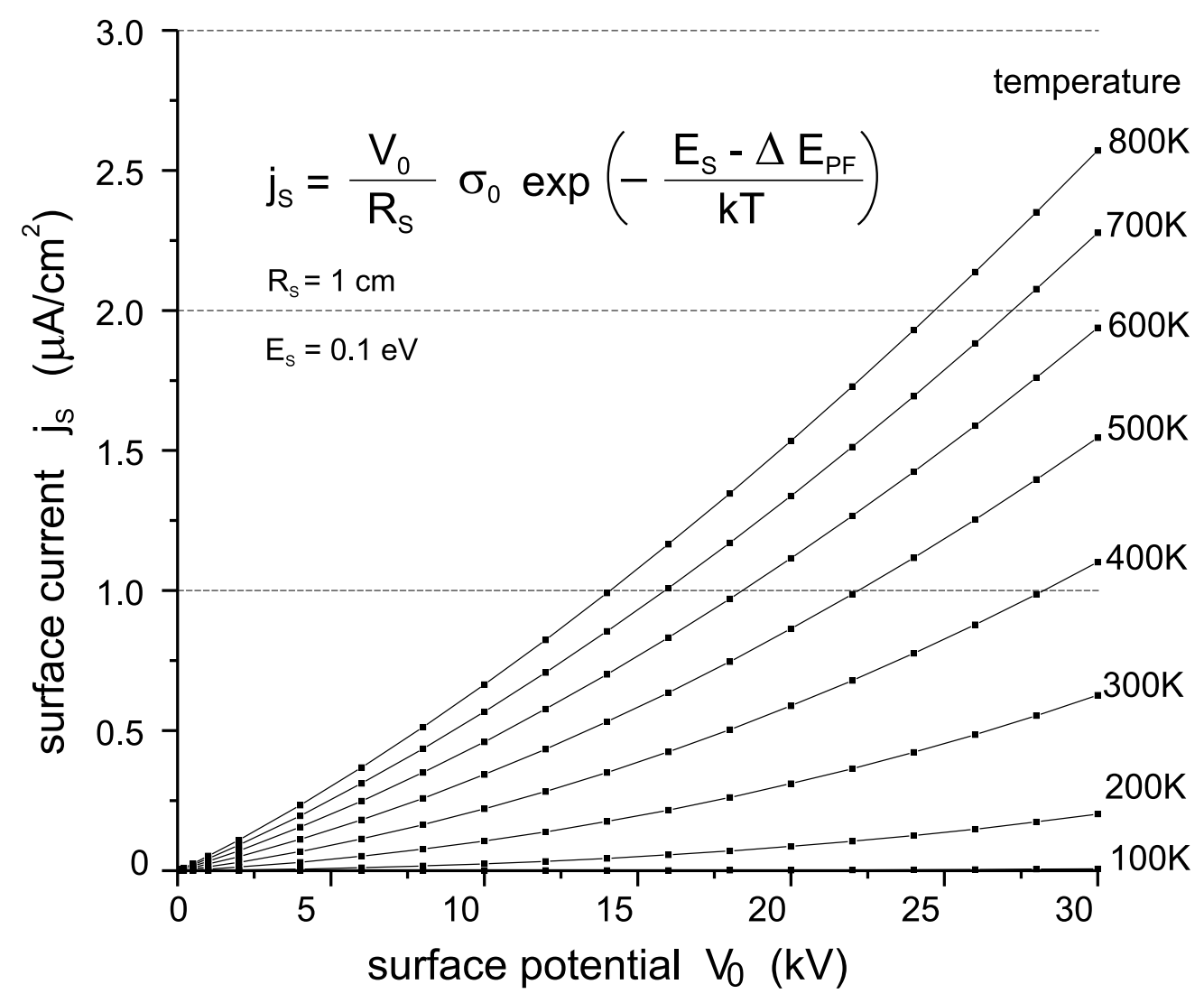

Fig. 9 

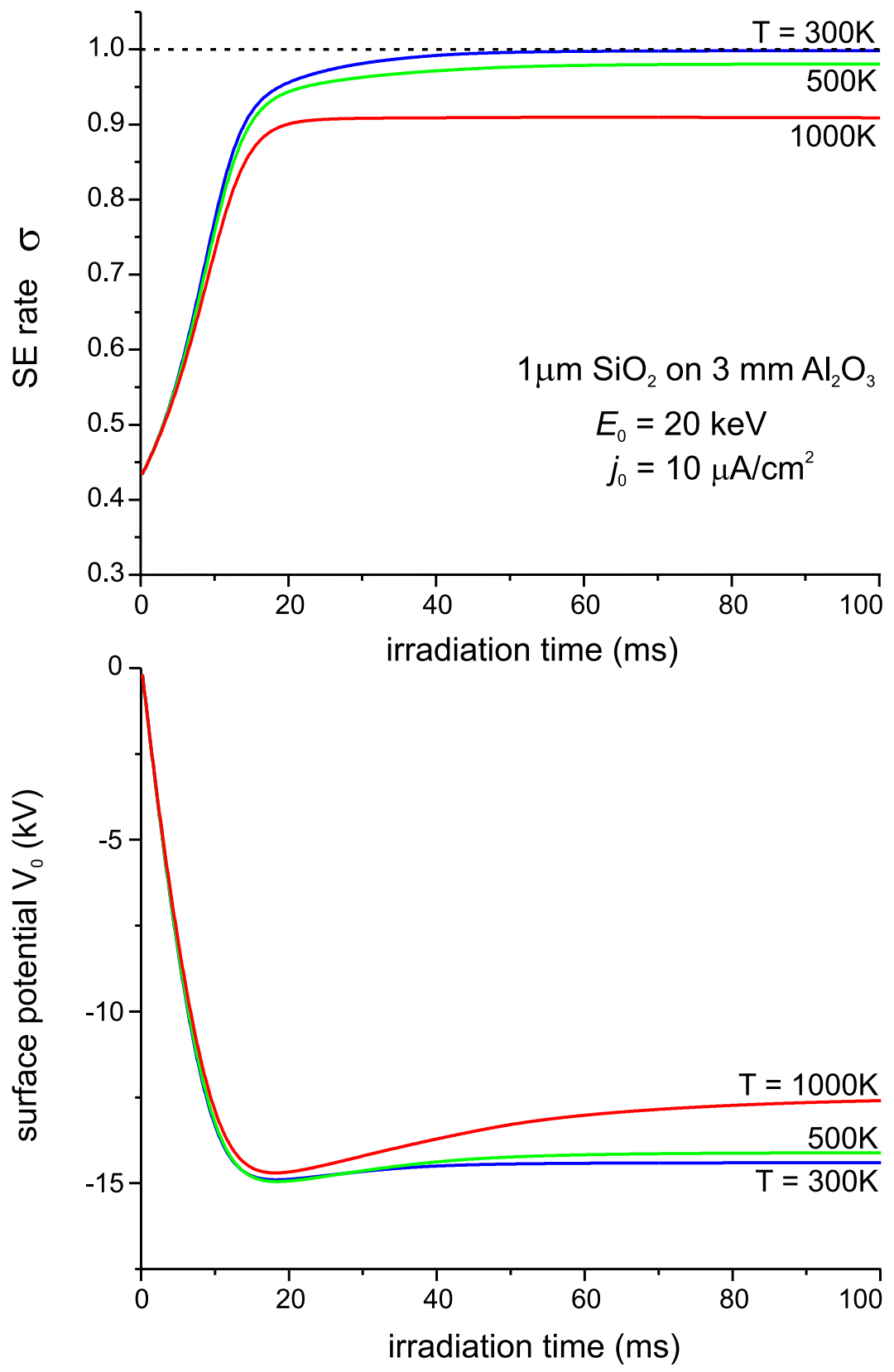

Fig. 10 


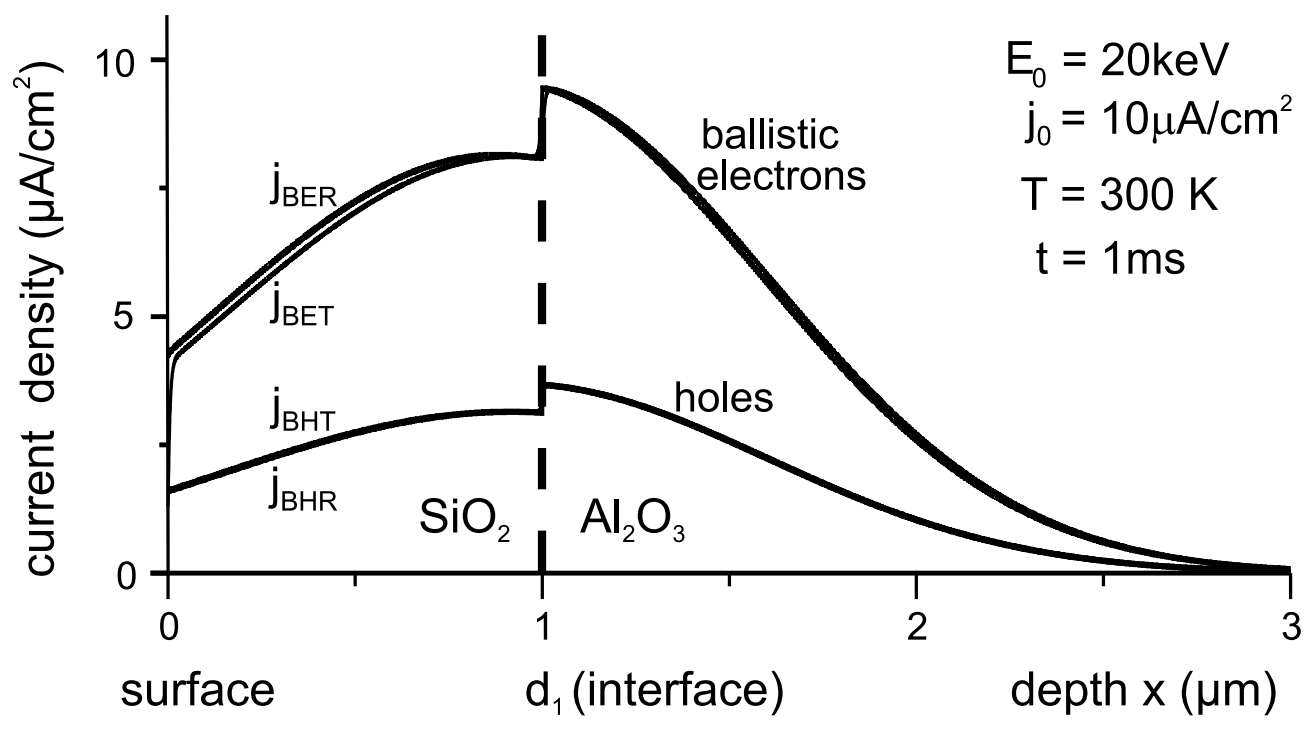

Fig. 11 

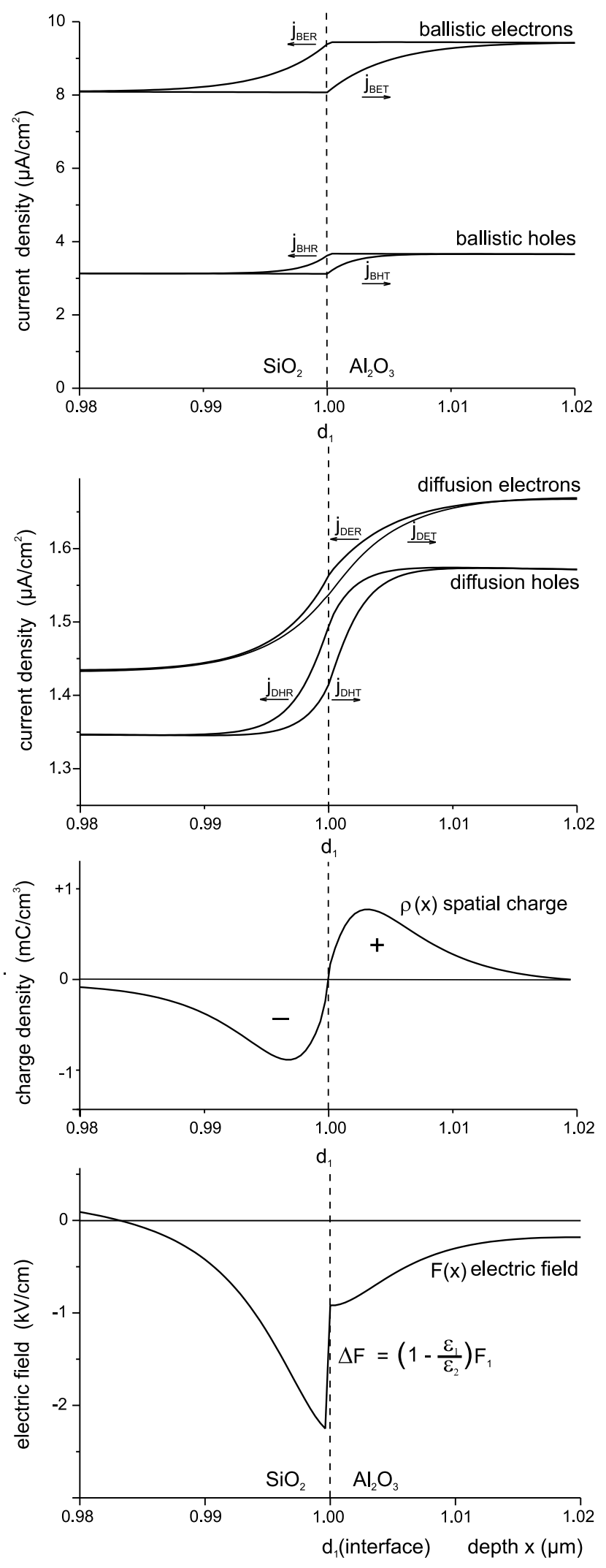

Fig. 12 

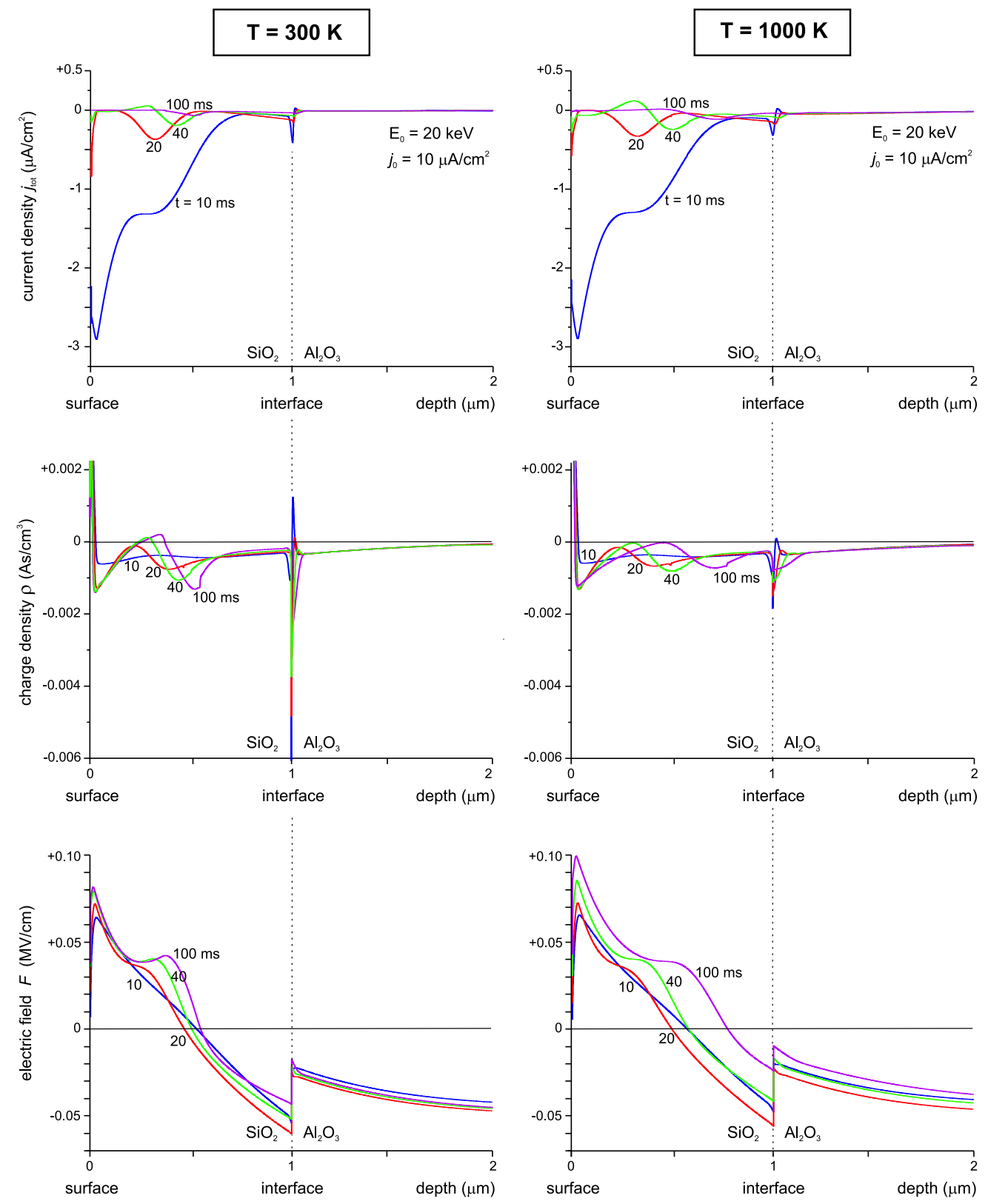

Fig. 13 


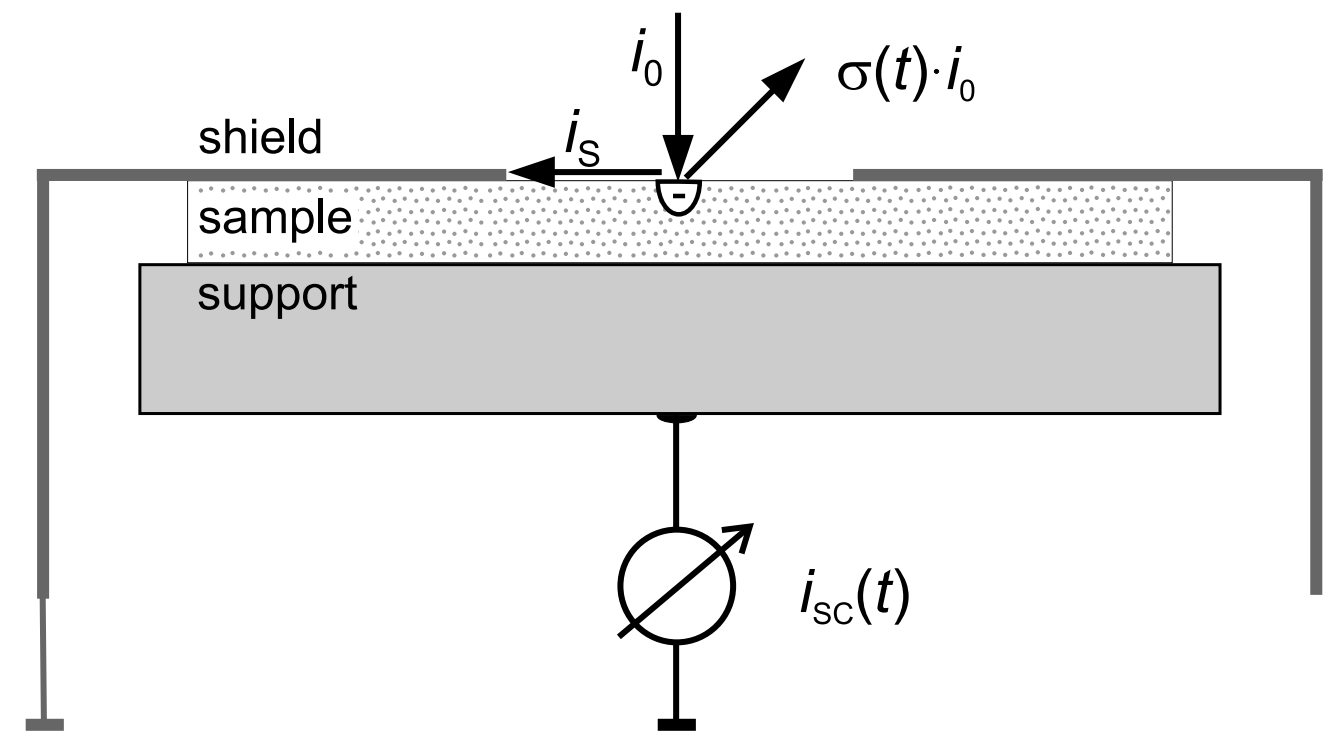

Fig. 14 


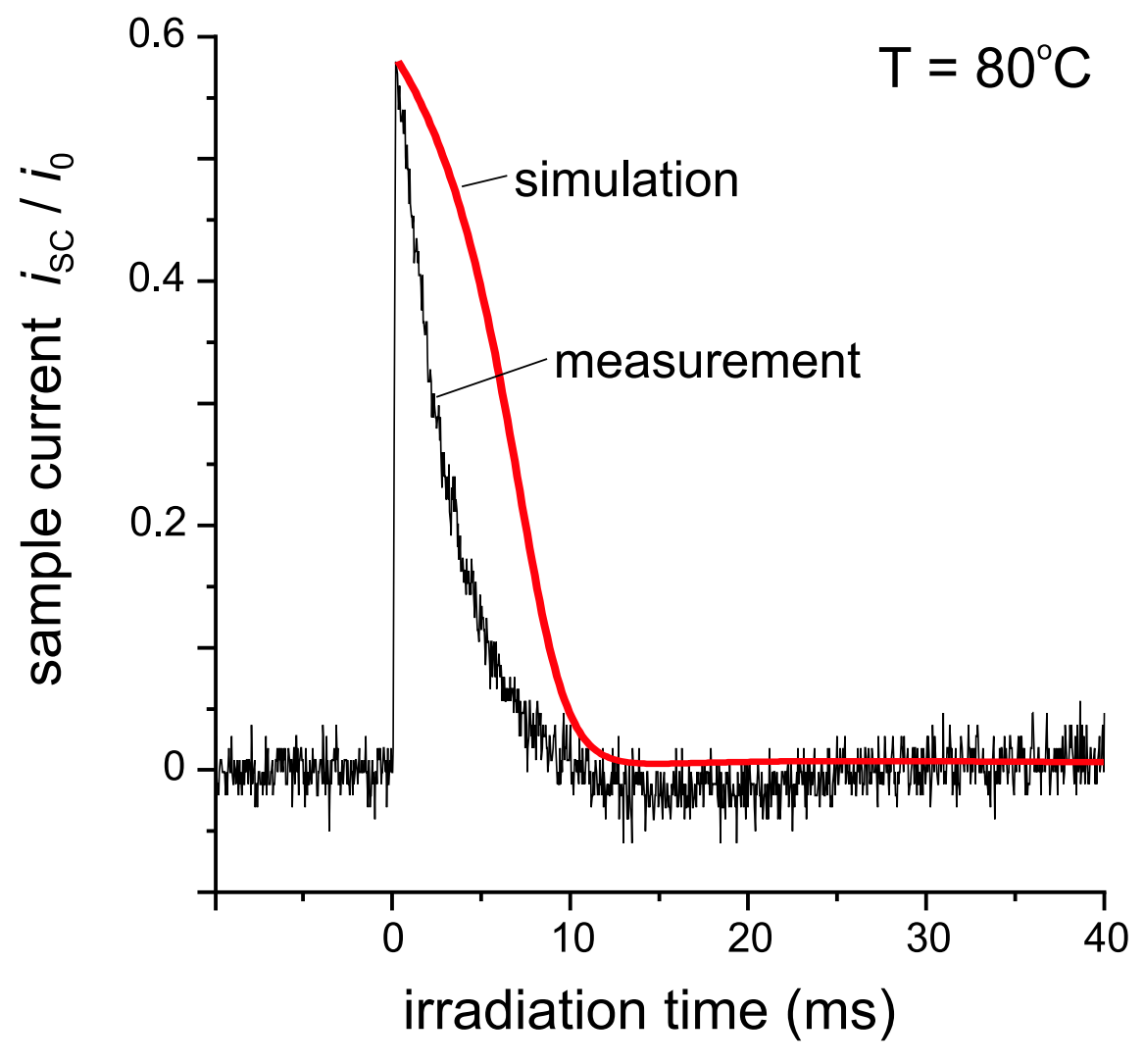

Fig. 15 